\title{
An Observational Analysis of Three Extreme Rainfall Episodes of 19-20 July 2016 along the Taihang Mountains in North China
}

\author{
RUDI XIA \\ State Key Laboratory of Severe Weather, Chinese Academy of Meteorological Sciences, Beijing, China \\ DA-LiN ZHANG \\ State Key Laboratory of Severe Weather, Chinese Academy of Meteorological Sciences, Beijing, China, \\ and Department of Atmospheric and Oceanic Science, University of Maryland, College Park, \\ College Park, Maryland
}

(Manuscript received 20 November 2018, in final form 27 July 2019)

\begin{abstract}
This study examines the synoptic- and mesoscale processes leading to the generation of three extreme rainfall episodes with hourly rates of greater than $100 \mathrm{~mm} \mathrm{~h}^{-1}$ over the southern, middle, and northern portions of the eastern foothills of Mt. Taihang in North China on 19-20 July 2016. The extreme rainfall episodes took place over the 200-600-m elevation zones in the southern and northern portions but also over the lower elevations in the middle portion of the target region, sequentially during late morning, early evening, and midnight hours. Echo training accounted for the development of a linear convective system in the southern region after the warm and moist air carried by a southeasterly low-level jet (LLJ) was lifted to condensation as moving across Mt. Yuntai. In contrast, two isolated circular-shaped convective clusters, with more robust convective cores in its leading segment, developed in the northern region through steep topographical lifting of moist northeasterly airflow, albeit conditionally less unstable. Extreme rainfall in the middle region developed from the convergence of a moist easterly LLJ with a northerly colder airflow associated with an extratropical cyclogenesis. Results reveal that the LLJs and associated moisture transport, the intensifying cyclone interacting with a southwest vortex and its subsequent northeastward movement, and the slope and orientation of local topography with respect to and the stability of the approaching airflows played different roles in determining the timing and location, the extreme rainfall rates, and convective organizations along the eastern foothills of Mt. Taihang.
\end{abstract}

\section{Introduction}

An extensive extreme rainfall event took place along a south-north-oriented zone of $100-\mathrm{km}$ width on the eastern foothills of Mt. Taihang during the period of $0100 \mathrm{LST}(\mathrm{LST}=\mathrm{UTC}+8 \mathrm{~h}) 19$ July to $0700 \mathrm{LST}$ 20 July 2016, with the maximum 30-h accumulated rainfall amount of $732 \mathrm{~mm}$ at Dongmaan, Henan Province (i.e., DMA station in Fig. 1a). During the 30-h period, heavy rainfall with the hourly rates of $43-92 \mathrm{~mm}$ dropped continuously at DMA from 0900 to 1800 LST 19 July, hereafter 19/09-19/18 (dd/hh), resulting in a 10 -h rainfall accumulation of $645 \mathrm{~mm}$. Six rain gauge stations distributed along the eastern foothills of Mt. Taihang recorded the hourly rainfall rates (HRRs) of greater than $100 \mathrm{~mm}$, with a record-breaking rate of

Corresponding author: Rudi Xia, xiarudi@gmail.com
$139 \mathrm{~mm} \mathrm{~h}^{-1}$ at Nandaguo, Hebei Province (i.e., NDG station in Fig. 1b). A climatological study by Luo et al. (2016) shows that 99.9 percentile of HHRs over the region of interest in July during the years of 19812015 was about $60 \mathrm{~mm} \mathrm{~h}^{-1}$. So, an HRR of greater than $100 \mathrm{~mm} \mathrm{~h}^{-1}$ could be considered herein as an extreme rainfall episode. This extreme rainfall event has left 53 deaths and 86 missing people in Hebei and Henan Provinces. About 141000 houses collapsed and 718000 ha of crops were damaged over the region, leading to a direct economic loss of $\$ 1.5$ billion (U.S dollars).

Lei et al. (2017) attributed the development of this extreme rainfall event simply to the genesis of an extratropical cyclone (ETC, Fig. 2), which resulted from the vertical coupling of a northwesterly traveling midlevel trough with a mesoscale vortex located in southwest China, and its interaction with the general 


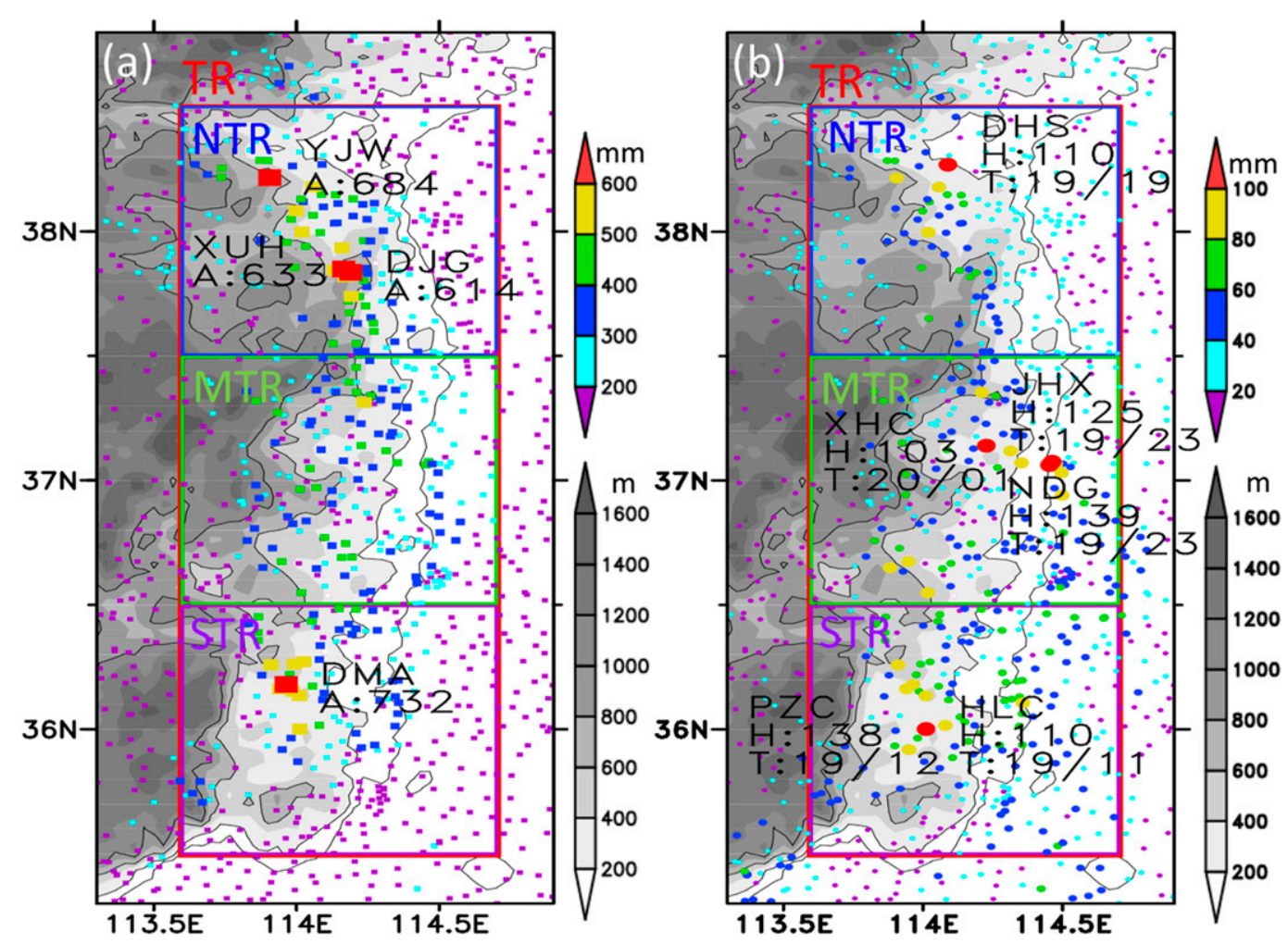

FIG. 1. (a) Distribution of the $30-\mathrm{h}$ accumulated rainfall ( $\mathrm{mm}$, colored squares) and (b) the HRRs $\left(\mathrm{mm} \mathrm{h}^{-1}\right.$, colored dots) in TR and its periphery from 0100 LST 19 Jul to 0700 LST 20 Jul 2016. Rain gauge stations with accumulated extreme rainfall amounts ("A": mm), and extreme HRRs ("H": $\mathrm{mm} \mathrm{h}^{-1}$ ) are indicated in (a),(b), respectively; and the extreme rainfall occurrence time ("T": $d d / h h$ LST) is also given in (b). Terrain is shaded in gray, with the contours of 100, 200, 600, and $1000 \mathrm{~m}$ elevations. Red, purple, green, and blue rectangles denote the subregions of TR, STR, MTR, and NTR, respectively. Note that both NDG and JHX stations, and both PZC and HLC stations are very close to each other, respectively.

orientation of Mt. Taihang. However, it remains unclear why and how such extreme rainfall amounts were generated mostly along the eastern foothills of Mt. Taihang, especially over certain elevation range of $100-\mathrm{km}$ width. What were the impacts of complex topography of Mt. Taihang in relation to the ETC genesis on the extreme rainfall production? Why could several major extreme rainfall episodes take place differently during the evening hours? Thus, we are motivated to address the above questions through a comprehensive multiscale observational analysis of the extreme rainfall event.

Previous studies have highlighted the following three key factors causing a heavy rainfall event: ample moisture supply, favorable uplifting, and long duration of rainfall (Doswell et al. 1996; Lin et al. 2001; Rebora et al. 2013), in addition to the presence of a conditionally unstable environment. Moisture supply in an extreme rainfall event is often related to the presence of a low-level jet (LLJ), which transports moisture of tropical origin to higher latitude regions (e.g., Zhang and Fritsch 1986; Chen and Yu 1988; Lin et al. 2001;
Durkee et al. 2012; Chen et al. 2014). A narrow corridor of such a water vapor transport channel in North America is known as an atmosphere river (e.g., Zhu and Newell 1998; Moore et al. 2012). Sustained rainfall events require the presence of favorable quasigeostrophic forcing, frontal or orographic lifting, mesoscale cold outflow boundaries, and thermal inhomogeneity including the urban heat island effect to facilitate continuous convective initiation (Baik et al. 2001; Zhang and Zhang 2012; Xu et al. 2012; Houze 2012; Bao and Zhang 2013; Zhong and Yang 2015; Li et al. 2017a).

Of importance is the organizational mode of mesoscale convective systems, which is the primary producer of extreme rainfall events in the United States and China (Schumacher and Johnson 2005, 2006; Moore et al. 2012; Jessup and Colucci 2012; Zhang et al. 2013; Luo et al. 2014; Luo and Chen 2015). For example, sustaining rainfall could occur when thunderstorms move along a linear MCS with little displacement in the line-normal direction (Parker and Johnson 2000; Schumacher and Johnson 2006), or when new 


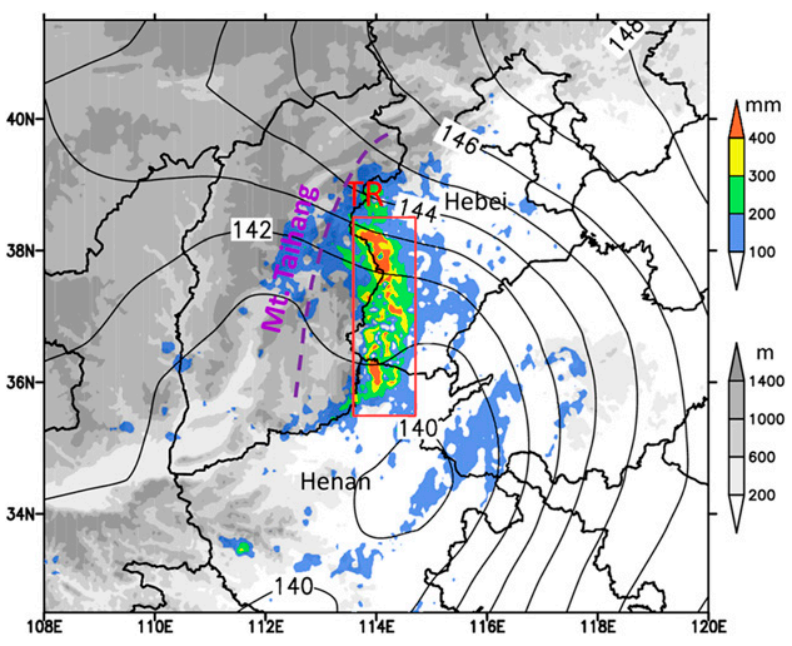

FIG. 2. Distribution of the $30-\mathrm{h}$ accumulated rainfall (mm, shaded) from 0100 LST 19 Jul to 0700 LST 20 Jul 2016, superimposed with $850-\mathrm{hPa}$ geopotential height (contoured at 10-gpm intervals) at 2000 LST 19 Jul 2016. Black curved lines show provincial borders, with provincial names denoted in black. The gray shaded areas represent topography $(\mathrm{m})$ with the ridge of Mt. Taihang denoted by dashed lines. Red rectangle denotes TR.

thunderstorms are initiated sequentially along a cold outflow boundary where older cells dissipate, the socalled back building, forming a quasi-stationary MCS (Bluestein and Jain 1985; Corfidi 2003; Schumacher and Johnson 2005, 2009; Zheng et al. 2013). A more common organizational mode for extreme rainfall events is the movement of a series of thunderstorms along the same path by a prevailing steering flow, the so-called echo training (Doswell et al. 1996; Moore et al. 2012; Zhang et al. 2013). Recently, the echo training concept has been extended to include rainband training, both were found to play important roles in extreme rainfall-producing MCSs in East and South China (Luo et al. 2014; Wang et al. 2014). Although considerable progress has been made in understanding the processes leading to various extreme rainfall events, predicting when and where an extreme rainfall event may occur by today's most up-to-date operational models is still a challenging task (Zhang et al. 2013; Schumacher 2017). In particular, our understanding of multiscale interactions involved in extreme rainfall production over mountainous regions is very limited.

Heavy rainfall events occur frequently in North China during the summer monsoon season, more so in July, which have produced tremendous economic losses and casualties each year (Tao 1980; He and Zhang 2010; Chen et al. 2012; Zhang et al. 2013; Zhong and Yang 2015; Zhong et al. 2015; Luo et al. 2016; Xia et al. 2018). A statistical study by Luo et al. (2016) shows that North China is one of the two major regions where very high HRRs occur in China. Moreover, these high hourly rainfall records tend to occur more frequently over the eastern foothill regions than the eastern plain regions (e.g., Li et al. 2017b), although the opposite is true for the distribution of seasonally averaged hourly rainfall intensity. However, few studies have been performed to examine why the above phenomena take place, although several hypotheses have been put forward, such as the interaction of a low-level vortex, a shearline, a cold front, a LLJ interacting with local topography as well as the echo training process (Su et al. 2011; Luo et al. 2016; He and Zhang 2010; Chen et al. 2012; Zhang et al. 2013; Zhong et al. 2015). Thus, the main purpose of this study is to examine various processes leading to the generation of the extreme rainfall event over the eastern foothills of Mt. Taihang on 19-20 July 2016 by addressing several questions raised earlier.

The next section describes the data and methodology used for this study. Section 3 shows the relationship between rainfall intensity and terrain elevation associated with the extreme rainfall event. Section 4 presents the associated synoptic conditions and moisture supply. Section 5 focuses on convective organization and the mesoscale processes leading to the development of several extreme hourly rainfall episodes over certain elevation range. Section 6 discusses the impact of orography on triggering the extreme rainproducing convective systems. A summary and conclusions are given in the final section.

\section{Data and methodology}

In this study, surface observations with $15-20-\mathrm{km}$ resolution over North China are used to investigate the spatial distribution of rainfall and surface meteorological fields (see Fig. 3). The temporal resolution is as high as $1 \mathrm{~min}$ for rain gauge observations, and as high as $5 \mathrm{~min}$ for surface winds, temperature, pressure, and dewpoint temperature. The 6-hourly and monthly mean European Centre for Medium-Range Forecasts interim reanalysis (ERA-Interim) data are used to examine large-scale circulations. Conventional upper-air soundings located on the east of the Mt. Taihang (i.e., at Zhengzhou and Xingtai), are used to examine stability and vertical flow profiles of upstream atmosphere. The vertically integrated precipitable water $(\mathrm{PW})$ observed by seven ground-based GPS-Met stations, shown in Fig. 3, is used to estimate the evolution of moisture supply during the extreme rainfall event.

S-band Doppler radars along the eastern foothills of Mt. Taihang (i.e., at Puyang and Shijiazhuang), are used to study convective organization modes (see Fig. 3 for 


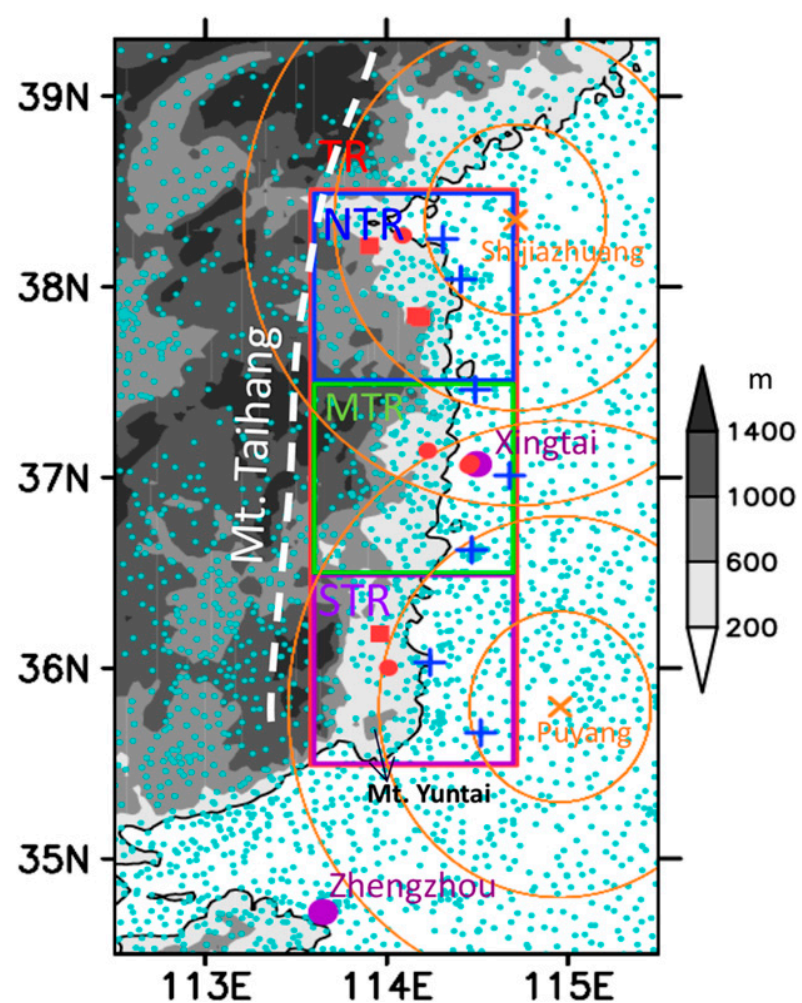

FIG. 3. Distribution of automated surface weather stations (cyan dots), radar stations (orange crosses), GPS-Met stations (blue crosses), and conventional upper-air stations (i.e., Zhengzhou and Xingtai denoted by purple solid circles) over the target domain along the eastern foothills of the Mt. Taihang (with its ridge denoted white dashed lines). Orange circles show the distances of 50, 100 , and $150 \mathrm{~km}$ from the radar stations. Red solid squares and circles show stations with the 30 -h accumulated rainfall of higher than $600 \mathrm{~mm}$ and stations with the maximum hourly rainfall of higher than $100 \mathrm{~mm}$ from 0100 LST 19 Jul to 0700 LST $20 \mathrm{Jul} 2016$, respectively. Gray shadings represent topography (m) with $200-\mathrm{m}$ elevation contour in black. An arrow is used to indicate the location of Mt. Yuntai. Rectangles in red, purple, green, and blue denote TR, STR, MTR, and NTR, respectively; similarly for the rest of figures. The three subregions of TR have the same size of $1^{\circ}$ latitude $\times 1.1^{\circ}$ longitude

their locations). These $\mathrm{S}$ band radars use the WSR-98D mode, which is similar to WSR-88D mode, and VCP21 scan strategy, which completes a volumetric scan on nine elevations including $0.5^{\circ}, 1.5^{\circ}, 2.4^{\circ}, 3.4^{\circ}, 4.3^{\circ}, 6.0^{\circ}$, $9.9^{\circ}, 14.6^{\circ}$, and $19.5^{\circ}$ in every $6 \mathrm{~min}$ (Yu et al. 2006). The gate width is $250 \mathrm{~m}$ and the maximum unambiguous ranges for reflectivity and velocity are 460 and $230 \mathrm{~km}$, respectively. Because of the atmospheric refraction of electromagnetic waves, the real detection ranges of radar reflectivity of a constant altitude plane position indicator (CAPPI) at 3 and $4 \mathrm{~km}$ are roughly 180 and $210 \mathrm{~km}$, respectively. The operationally distributed PUP and RPG software, which are subsystems of the U.S. WSR-88D system (Crum and Alberty 1993), are used to retrieve cross sections of radar reflectivity and radial wind fields. To obtain CAPPI maps, radar data originally on polar coordinates are converted to data on Cartesian coordinates, with $0.01^{\circ}$ horizontal resolution and 20 vertical levels having a $0.5-\mathrm{km}$ resolution below $6 \mathrm{~km}$. Before the conversion, some data quality controls (e.g., excluding surface clutter) have been performed using the system developed by the State Key Laboratory of Severe Weather of the Chinese Academy of Meteorological Science (Wang et al. 2009).

To facilitate comparing extreme hourly rainfall characteristics over different regions during different periods, we define a target region (hereafter TR) of this study, with the southern, middle, and northern portions of TR named as STR, MTR and NTR, respectively (Fig. 3). The 3- or 4-km CAPPI radar reflectivity, that provides appropriate radar observation range with little impact of bright band signature (Steiner et al. 1995), in the above three subregions will be analyzed and compared.

Terrain data with $0.01^{\circ}$ resolution are used to examine the correlation between topography and rainfall production. Note that this terrain resolution may not represent precise elevations of surface weather stations, especially for those far away from the data grids, but it is appropriate for analyzing basic topographical features. Of our concern are the topographical structures along the eastern foothills of Mt. Taihang because the approaching flows tend to run over the south-northoriented Mt. Taihang. In particular, Fig. 1 shows that the orientation and terrain slope differ from STR to NTR, with Mt. Yuntai having the peak elevation of $1308 \mathrm{~m}$ near the southern border of STR. That is, STR and NTR exhibit larger terrain slopes for southerly and easterly impinging flows, respectively, than those for an easterly flow in MTR, with a south-southwest to north-northeast orientation in STR and MTR but a northwest to southeast orientation in NTR. In addition, the terrain slope above 600-m elevation in STR is larger than the other two subregions, while the terrain slope below $600 \mathrm{~m}$ in NTR is large in its southern portion but small in the middle portion. As will be seen in the next few sections, these terrain slopes and orientations as well as the location of Mt. Yuntai have different implications to the generation of various extreme rainfall episodes.

\section{Relationship between rainfall and terrain elevations}

Figure 1a shows the map of 30-h accumulated rainfall associated with the extreme rainfall event. In general, the accumulated rainfall amounts over the lower-elevation regions [i.e., terrain elevations $<200 \mathrm{~m}$ above mean sea 

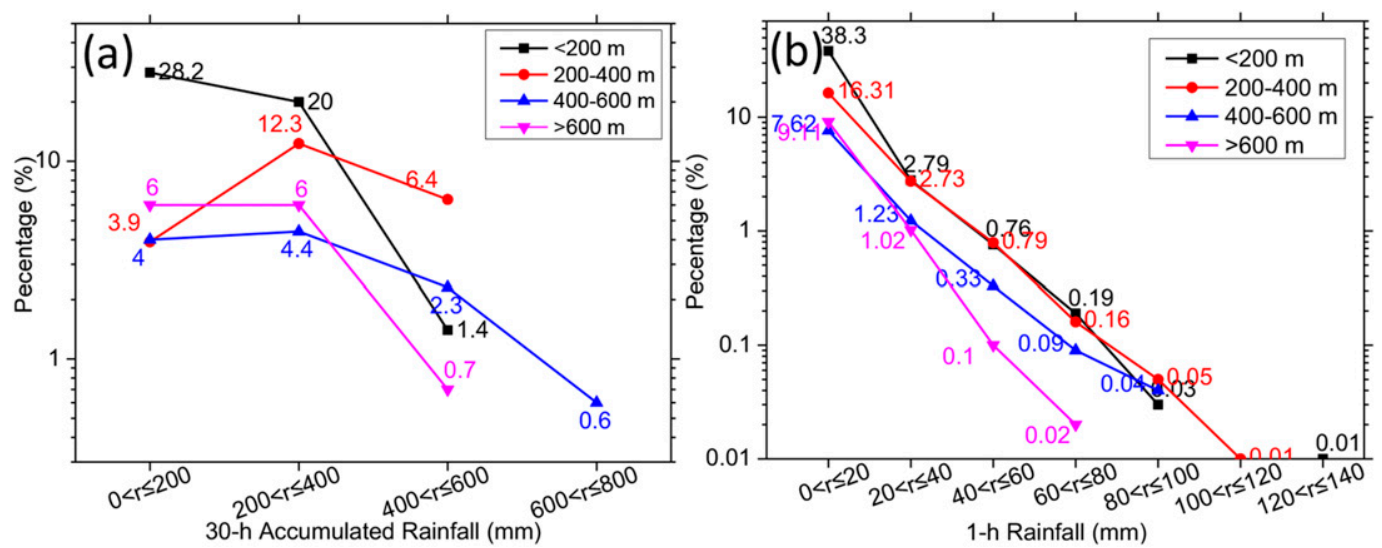

FIG. 4. (a) Percentage of stations from the total stations over TR at varying terrain elevations (at 200-m intervals below $800 \mathrm{~m}$ ) that recorded various 30-h accumulated rainfall amounts (at 200-mm intervals) during 0100 LST $19 \mathrm{Jul}$ to 0700 LST $20 \mathrm{Jul} 2016$. About $96.2 \%$ of stations recorded some rainfall amounts during the 30 -h period. There are 361, 162, 83, and 93 stations located at the terrain elevations of 0-200, 200-400, 400-600, and >600 m, respectively, accounting for $52 \%, 23 \%, 12 \%$, and $13 \%$ of the total stations. (b) As in (a), but for the HRRs (at $20 \mathrm{~mm} \mathrm{~h}^{-1}$ intervals) during the above 30 -h heavy rainfall period. About $81.7 \%$ of stations recorded some HRRs during the 30 -h period.

level (MSL)] were less than $200 \mathrm{~mm}$, and they increased toward the sloping mountains to the west, with more than $600 \mathrm{~mm}$ recorded at four stations, as highlighted by solid squares; the maximum value of $732 \mathrm{~mm}$ was observed at DMA in STR. Of interest is that all the extreme rainfall amounts were recorded at the 400-600-m elevation stations. In view of the dependence of rainfall amounts on terrain elevations, Fig. 4a shows the percentages of rain gauge stations at various terrain elevations, given at 200-m intervals, that recorded different rainfall amounts at every $200 \mathrm{~mm}$. Stations with accumulated rainfall of less than $200 \mathrm{~mm}$ were mostly distributed over foothills with elevation of $0-200 \mathrm{~m}(28.2 \%)$, and the next over mountains with elevations of greater than $600 \mathrm{~m}(6 \%)$ and then $400-600 \mathrm{~m}(4.4 \%)$. In general, the percentage of stations at all the terrain elevation intervals decreases with increasing accumulated rainfall amounts from $0-200$ to $600-800 \mathrm{~mm}$, except for the 200-400-m elevation stations whose percentage had an increase in the $200-400-\mathrm{mm}$ rainfall interval. Although the stations with elevations of less than $200 \mathrm{~m}$ constitute $52 \%$ of the total stations, they only took up $13.0 \%$ in stations recording rainfall of $400-600 \mathrm{~mm}$ and did not record rainfall higher than $600 \mathrm{~mm}$. In contrast, the 200-400- and 400-600-m elevation stations accounted for $23 \%$ and $12 \%$ of the total stations, respectively, they took up $59.3 \%$ and $21.3 \%$ in stations recording rainfall of $400-600 \mathrm{~mm}$, respectively. This analysis indicates clearly that heavier rainfall accumulations took place over 200-600-m elevation zones.

Figure $1 \mathrm{~b}$ shows the distribution of the maximum HRRs recorded by each station during the 30 -h period.
The highest HRR of $139 \mathrm{~mm} \mathrm{~h}^{-1}$ was recorded at 19/23 by NDG with terrain elevation of $86 \mathrm{~m}$ in MTR. This rate was much higher than the maximum HRR of $85 \mathrm{~mm}$ recorded in Beijing's high-impact extreme rainfall event on 21 July 2012 (Zhang et al. 2013). Its neighboring stations, JHX and XHC, recorded 125 and $103 \mathrm{~mm} \mathrm{~h}^{-1}$ at 19/23 and 20/01, respectively. There were another three stations roughly at $200-600-m$ elevation zone showing HRRs exceeding $100 \mathrm{~mm} \mathrm{~h}^{-1}$ : DHS in NTR with $110 \mathrm{~mm} \mathrm{~h}^{-1}$ at $19 / 19$, and PZC and HLC both in STR with $138 \mathrm{~mm} \mathrm{~h}^{-1}$ at $19 / 12$ and $110 \mathrm{~mm} \mathrm{~h}^{-1}$ at 19/11, respectively. These high HRRs were likely produced by the frequent passage of convective cells with the high rainfall rates of over $6 \mathrm{~mm}(5 \mathrm{~min})^{-1}$ (Fig. 5). In particular, larger HRRs correspond to higher frequencies of high 5-min rainfall (e.g., at NDG, PZC, and JHX).

Figure $4 \mathrm{~b}$ shows that the highest HRRs were recorded at stations of terrain elevations of $0-200 \mathrm{~m}$ and the next at terrain elevations of $200-400 \mathrm{~m}$, which differs from the distribution characteristics of heavier total accumulated rainfall. The proportions of stations at all elevation intervals had similar decreasing trend with increasing HRRs. The majority of stations (71\%) recorded HRRs of less than $20 \mathrm{~mm} \mathrm{~h}^{-1}$ during the 30 -h heavy rainfall periods. By comparison, the percentage for HRRs of greater than $60 \mathrm{~mm} \mathrm{~h}^{-1}$ was only $0.6 \%$, implying that high HRRs were of low-frequency during this event.

Some differences in the rainfall dependence on terrain elevations can be clearly seen by comparing the distribution of extreme rainfall locations in the three 


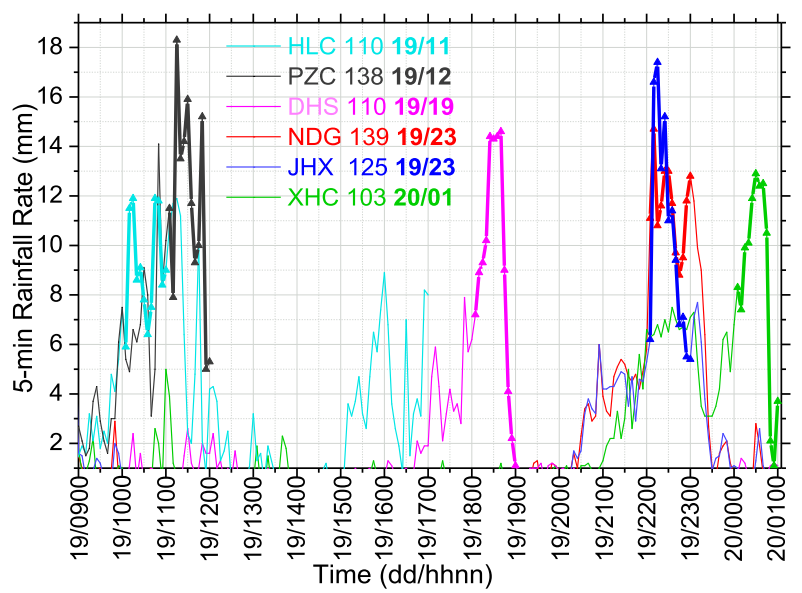

FIG. 5. Time series of 5-min rainfall rates at rain gauge stations with HRRs of greater than $100 \mathrm{~mm} \mathrm{~h}^{-1}$. The extreme rainfall episodes are highlighted in bold and with triangles. Inset legends show stations with extreme HRRs $\left(\mathrm{mm} \mathrm{h}^{-1}\right)$ and extreme rainfall occurrence times $(\mathrm{dd} / \mathrm{hh})$.

subregions (cf. Figs. 1a,b). Apparently, the accumulated rainfall records higher than $500 \mathrm{~mm}$ in NTR were distributed around 600-m elevation stations, which was also true for the maximum HRRs of higher than $80 \mathrm{~mm} \mathrm{~h}^{-1}$, except at DHS. In contrast, both the maximum accumulated rainfall and the maximum HRR in STR were distributed at lower-elevation stations (i.e., 200-600 m). In MTR, only one station, with a terrain elevation of $1007 \mathrm{~m}$, recorded more than $500-\mathrm{mm}$ accumulated rainfall. Moreover, the terrain elevations of stations recording the maximum HRRs of greater than $80 \mathrm{~mm} \mathrm{~h}^{-1}$ in MTR were lower than those in STR and NTR.

Since more pronounced rainfall took place over the 200-600-m elevation mountainous regions, it is of interest to examine the temporal evolution of the associated HRRs over TR. It is apparent from Fig. 6, in which the 200-600-m elevation regions are highlighted, that rainfall rates greater than $60 \mathrm{~mm} \mathrm{~h}^{-1}$ occurred over STR from the morning to late afternoon hours (i.e., 19/10 to 19/18), with the peak rate occurring in the midday. After a couple of hours of reduced rainfall occurrences, heavy hourly rainfall shifted to STR's lower-elevation areas to the east from $19 / 20$ to $19 / 23$. Such heavy rainfall rates did not begin in NTR until 19/14, with the subsequent increasing number of stations closer to the 600$m$ elevation contour recording HRRs of greater than $60 \mathrm{~mm} \mathrm{~h}^{-1}$. The heavy rainfall maintained in NTR until $19 / 22$ with the peak amount in the early evening. In contrast, heavy hourly rainfall in MTR occurred mainly during the following two periods: late afternoon to early evening hours (i.e., 19/17 to 19/19), which was the same as that occurred in NTR and STR, and late evening hours (i.e., 19/21 to 20/01) during which period the extreme hourly rainfall took place. The above rainfall evolutional characteristics could be understood in the context of larger-scale circulations interacting with local orography, which will be explored in section 5 .

\section{Synoptic settings}

Before examining the role of larger-scale flows interacting with local orography in producing the various extreme rainfall scenarios described in the preceding section, it is necessary to see the general synoptic-scale settings from the lower to upper troposphere during the extreme rainfall period. Figures $7 \mathrm{a}$ and $7 \mathrm{~b}$ show that TR was located ahead of a westerly trough at $200 \mathrm{hPa}$, with horizontal divergence of greater than $5 \times 10^{-5} \mathrm{~s}^{-1}$ to the south of an upper-level jet stream. Clearly, this divergence was at least favorable for the uplifting of moist conditionally unstable air for extreme rainfall production. Of course, part of this divergence could be a result of latent heat release due to the 12-h averaging of the 6-hourly ERA-Interim reanalysis used.

Figure $7 \mathrm{c}$ shows the presence of a midlevel westerly trough, referred earlier to as part of an ETC, to the west of TR, with warm (cold) advection ahead of (behind) its trough axis. This ETC-related trough extended southwestward, and tended to merge with another midlevel trough associated with a preexisting southwest vortex, whose closed circulation was mainly lower tropospheric (cf. Figs. 7c and 8a). Although its center moved little during the subsequent $6 \mathrm{~h}$ (Fig. 8b), its cyclonic circulation became elongated northeastward into the low pressure system over North China. A new vortex center (i.e., the ETC), which tilted southeastward from a closed low at $500 \mathrm{hPa}$ (cf. Figs. $8 \mathrm{c}$ and $7 \mathrm{~d}$ ), was seen on the south of TR at 19/20, with a cold front extending southwestward from the vortex center (Figs. 8c,d). Subsequently, the ETC moved slowly northeastward. The extreme rainfall event took place mainly during the ETC genesis stage (i.e., from 19/09 to 20/01) (Fig. 5). Thus, the associated latent heat release had also contributed greatly to the rapid development of the ETC (Lei et al. 2017).

Figure 8 also shows the important impact of the cyclonic wind directional changes with respect to the orientation of Mt. Taihang on the generation of extreme rainfall. That is, the prevailing wind direction in TR changed from southeasterly to easterly, and then eastnortheasterly during the 18 -h period of $19 / 08-20 / 02$, thereby providing an optimal setting for the topographical lifting of incoming moist air. As a result, rainfall intensified when the normal to terrain wind component increased. For example, the 6-h accumulated 

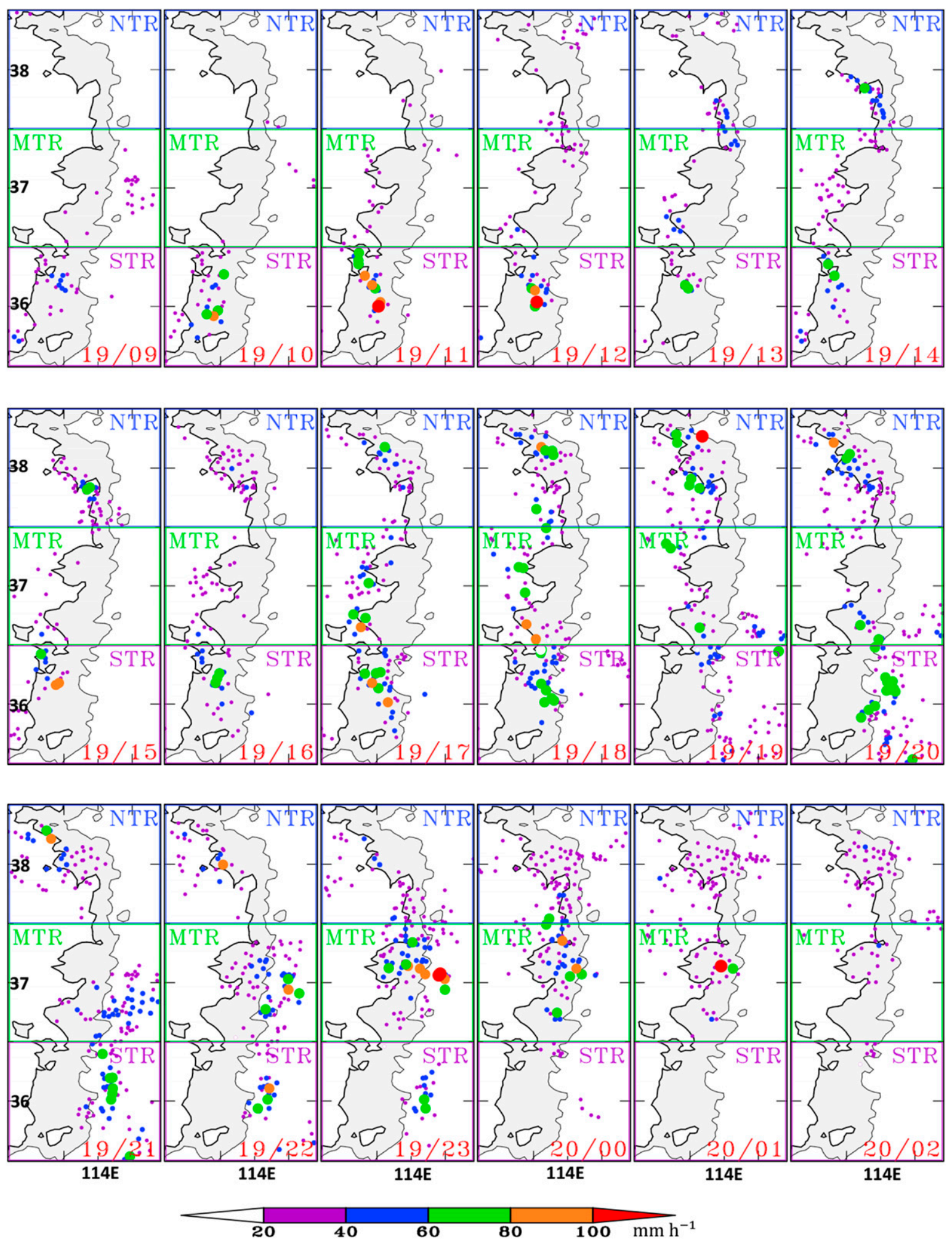

FIG. 6. Distribution of HRRs (dots, $\mathrm{mm} \mathrm{h}^{-1}$ ) over TR. Gray shadings with black curves represent terrain elevations between 200 and $600 \mathrm{~m}$. Times (LST) in form of dd/hh are shown in the lower right corners. Purple, green, and blue rectangles denote STR, MTR, and NTR, respectively. 

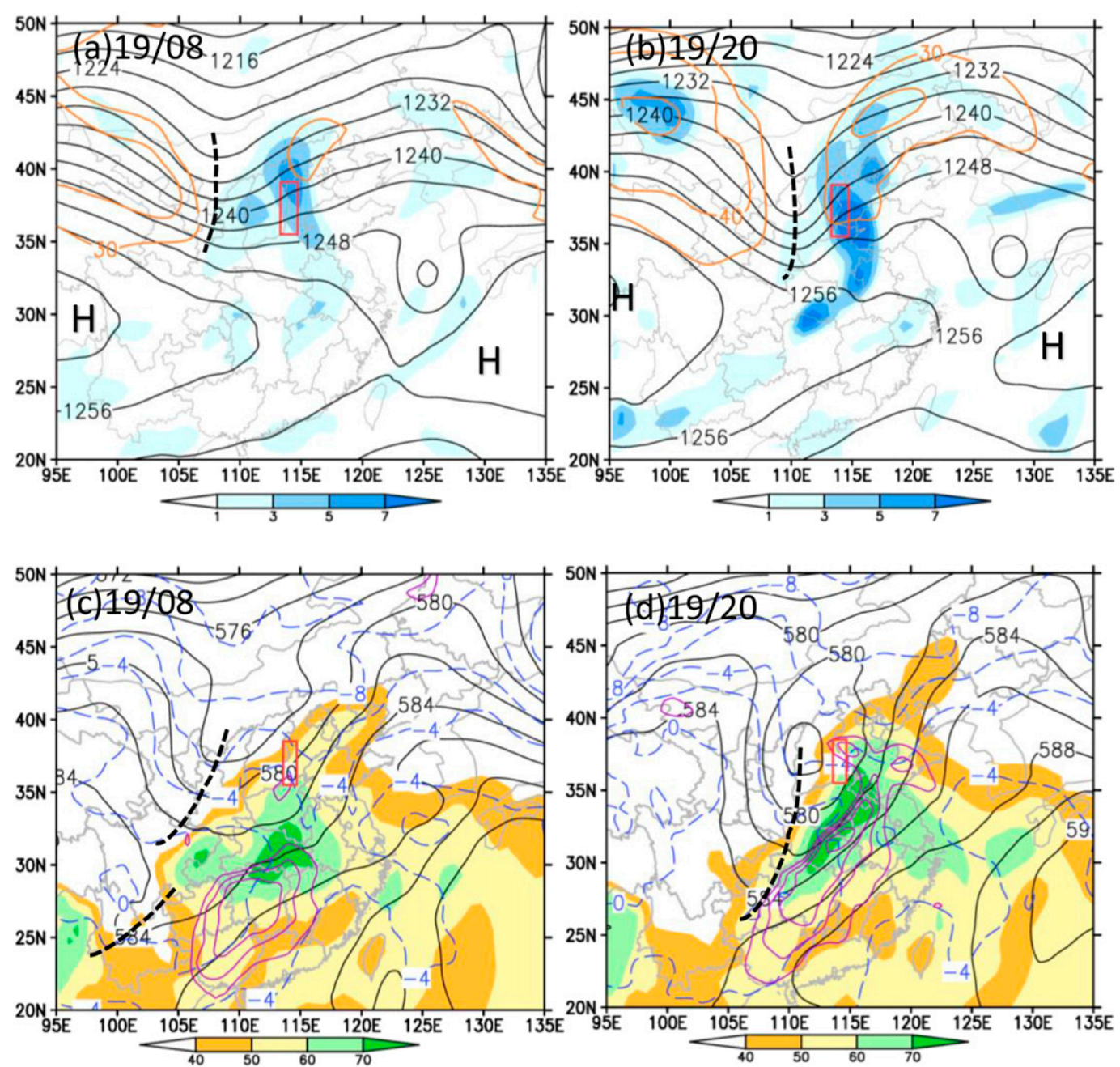

FIG. 7. Distribution of geopotential heights (black contoured at $40 \mathrm{gpm}$ intervals) with the trough axis denoted by dashed lines, horizontal wind speeds of greater than $30 \mathrm{~m} \mathrm{~s}^{-1}$ (orange contours), and horizontal wind divergence $\left(10^{-5} \mathrm{~s}^{-1}\right.$, shaded) at $200 \mathrm{hPa}$ at (a) 0800 and (b) $2000 \mathrm{LST} 19 \mathrm{Jul} 2016$. Distribution of 500-hPa geopotential height (black contoured at $20 \mathrm{gpm}$ intervals), 500-hPa temperature (blue contoured at $2^{\circ} \mathrm{C}$ intervals), and $850-\mathrm{hPa}$ wind speeds of greater than $12 \mathrm{~m} \mathrm{~s}^{-1}$ (purple contoured at $3 \mathrm{~m} \mathrm{~s}^{-1}$ intervals), and PW (mm, shaded) at (c) 0800 and (d) 2000 LST 19 Jul 2016. Red rectangles denote TR.

rainfall increased to more than $100 \mathrm{~mm}$ at $19 / 20$ and $20 / 02$ as the $850-\mathrm{hPa}$ winds in TR became nearly perpendicular to the eastern foothills of Mt. Taihang with the speeds increasing to $15-18 \mathrm{~m} \mathrm{~s}^{-1}$. In contrast, rainfall diminished by $20 / 20$ as the low-level winds became gradually paralleled to the eastern foothills of Mt. Taihang orientation as the ETC moved to higher latitudes (not shown). One may note that a rainbelt moved toward TR from the west under the influence of the midlevel trough prior to 19/14 (Figs. 8a,b), but it weakened as moving the downslope of Mt. Taihang. This indicates little impact of this rainbelt on the development of the extreme-rain-producing storms of interest.
Since extreme rainfall is always a rare event by definition, the genesis location of the ETC and its subsequent northward movement along the orientation of Mt. Taihang appear to be two of the major factors accounting for the extreme rainfall event occurring along the eastern foothills. Specifically, most ETCs during the summer months propagate across North China to the north of $40^{\circ} \mathrm{N}$, and they appear often as midlevel cutoff lows (Tao 1980; Hu et al. 2010). So, it is unusual to see the genesis of an ETC near $35^{\circ} \mathrm{N}$, as in the present case. As mentioned above, its genesis was aided by its merging with the preexisting southwest vortex. Its subsequent movement is also an important factor because an optimal setting for 

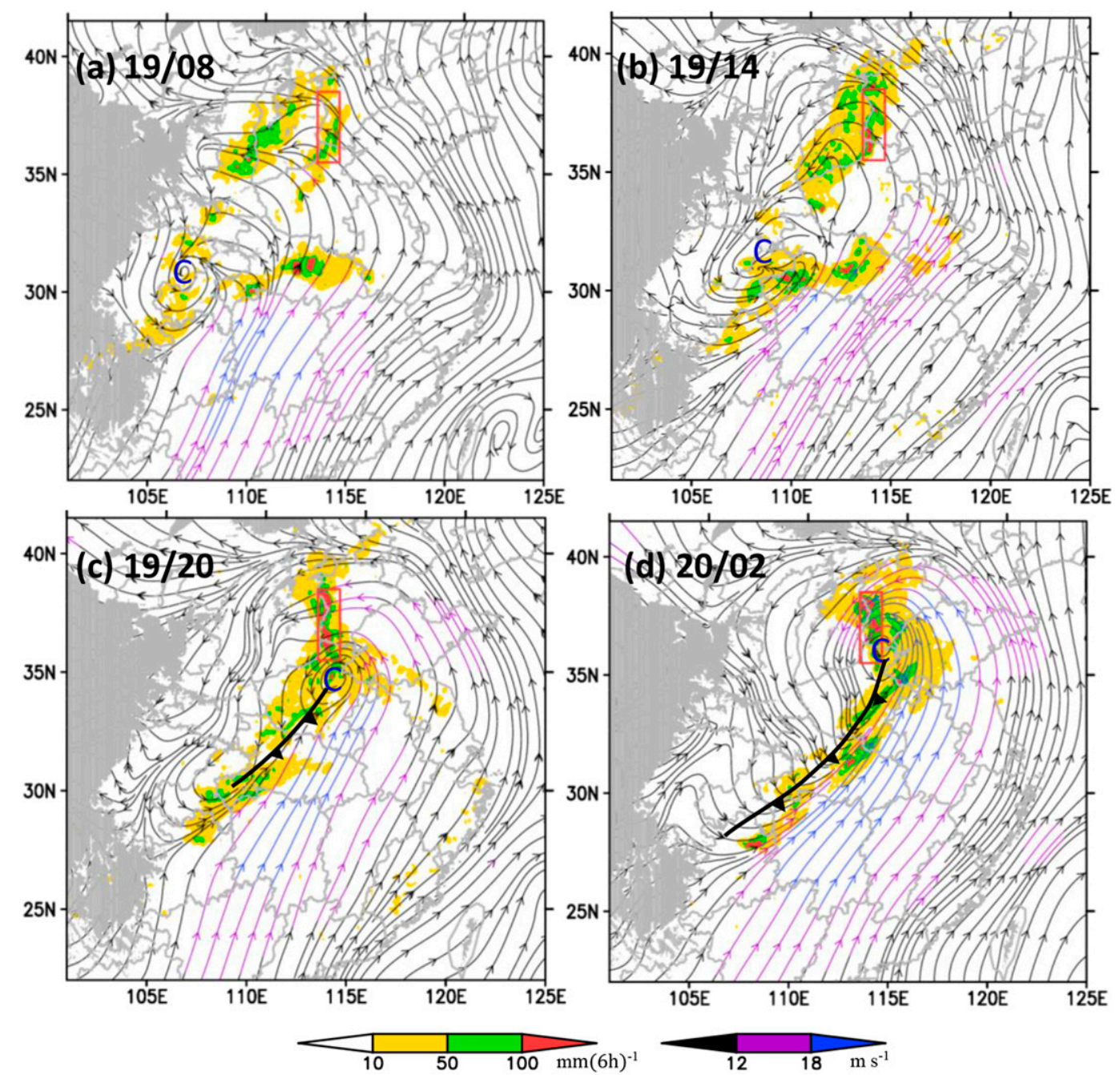

FIG. 8. Distribution of $850-\mathrm{hPa}$ streamlines from the ERA-Interim reanalysis, and 6-h rainfall amounts (mm, shaded) at selected times (given at the upper-left corner of each panel in form of dd/hh) on 19-20 Jul 2016. Gray shaded areas denote terrain elevations of greater than $1500 \mathrm{~m}$. Red rectangles denote TR. Sea level low pressure centers, denoted by "C," and surface cold fronts are shown.

topographical lifting could not occur if it did not move along the orientation of Mt. Taihang.

Another key factor related to this extreme rainfall event is the presence of a southeasterly LLJ with the maximum wind speed of greater than $21 \mathrm{~m} \mathrm{~s}^{-1}$ occurring ahead of the $850-\mathrm{hPa}$ trough axis (Fig. 7d). This LLJ clearly accounted for the northeastward and then northwestward transport of warm and moisture air of tropical origin toward TR. By 19/08, the leading portion of the LLJ has reached central China, resulting in high PW of greater than $70 \mathrm{~mm}$ on TR's upstream (Figs. 7c and 8a). As the LLJ extended farther northeastward and its exit region reached TR at 19/20, so is the tip of a PW tongue (Figs. 7d and 8b-d). A 19/20 sounding at Xingtai, which is close to NDG and JHX, to be shown in section 6, exhibited a southeasterly LLJ near $900 \mathrm{hPa}$ that should also contribute to moisture supply from the Yellow and East China Sea to TR. Figure 9 shows that the TR-average PW attained the highest value of $70 \mathrm{~mm}$ by $19 / 22$, at which time the LLJ has extended to TR. This was one hour prior to the occurrence of the highest HRR of $139 \mathrm{~mm}$ (cf. Figs. 9 and 1b). The highest PW recorded over TR (i.e., at STR) was as high as $84 \mathrm{~mm}$, which was much higher than the peak PW of $60 \mathrm{~mm}$ during Beijing's extreme rainfall event of 21 July 2012 (Zhang et al. 2013). By comparison, the PW recorded by the stations over NTR was obviously lower than that over MTR and STR during the extreme rainfall period, which was consistent with the relatively weaker HRRs in NTR. 


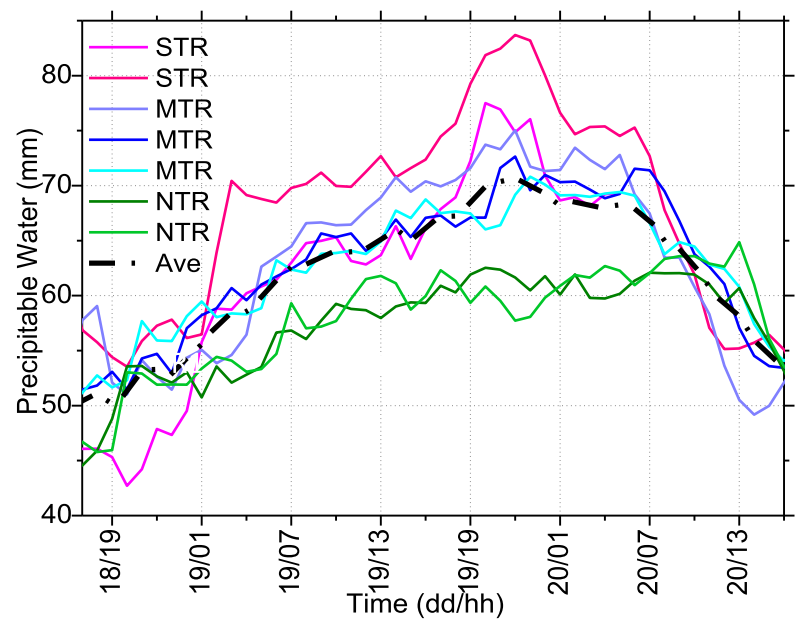

FIG. 9. Hourly variation of PW at the GPS-Met stations (see their distribution in Fig. 3) over TR. Mean values are shown by black dash-dotted lines. Inset legends show regions of the stations.

\section{Convective organization}

Since section 3 indicates that the extreme HRRs of greater than $100 \mathrm{~mm} \mathrm{~h}^{-1}$ occurred mainly during the following three time periods in STR, NTR, and MTR, respectively: 19/08-19/12, 19/16-19/20, and 19/21-20/01, we examine in this section the mesoscale processes leading to the generation of the three different extreme rainfall episodes. This is done through the analyses of surface winds, three-dimensional CAPPI radar reflectivity and radar radial winds during the extreme rainfall episodes over the above three subregions.

\section{a. Evolution of convective systems}

Figure 10 shows the $3-\mathrm{km}$ altitude CAPPI radar reflectivity and the surface wind fields in STR during 19/08 to $19 / 12$ in order to examine the evolution of convective cores or clusters, labeled as $1-7$, associated with the first convective core scenario. Here a convective cluster is defined as an aggregation of several convective cores when they were too close to identify. We see the development of 4 convective clusters over the upsloping region at 19/0802, in which cluster 2 consisted of several convective cores in a northwest-southeast orientation that coincided with a surface convergence line indicated by red-dashed lines in Fig. 10a. These convective systems tended to move north to northeastward. Meanwhile, several clusters (e.g., 3-6) were initiated along the south-north-oriented 200-600-m elevation zone (Figs. 10a-c), clearly as a result of terrain uplifting of the southeasterly warm-moist air.

Note the formation of clusters 4-6 in the northern fringe of Mt. Yuntai (Figs. 3 and 10a) during 19/0802 to $19 / 0850$ (dd/hhnn, Figs. 10a-c). All these convective cores/clusters plus those at their incipient stages began to be organized along the 200-600-m elevation zone. First, at 19/0908, clusters 3-6 merged to form cluster 7, and then, the latter extended northward to merge with a southern convective core of cluster 2 (Figs. 10d,e). A distinct convective line across DMA, PZC, and HLC formed to the north of Mt. Yuntai at 19/1003 (Fig. 10f). Of significance is that the above three stations recorded 85,88 , and $110 \mathrm{~mm} \mathrm{~h}^{-1}$ rainfall rates, respectively, in the subsequent 1-h period, during which the line-shaped organization was well maintained with only slight changes in orientation (Figs. 10g-i). Of further significance is that new convective cells were continuously initiated on the southern head of cluster 7, even up to 19/1200 and beyond, leading to the HRR of $138 \mathrm{~mm}$ at PZC station at 19/12 (Figs. 10j-1). This organizational mode (i.e., in which new convective cells repeatedly formed on the upstream of their predecessors and decaying cells moving downstream are replaced by stronger cells from upstream) resembled clearly the echo training phenomenon in heavy-rainfall-producing MCSs described by Doswell et al. (1996), Schumacher and Johnson (2005), and Luo et al. (2014).

Unlike the extreme rainfall episode in STR, NTR had a different convective organizational mode for extreme rainfall production (Fig. 11). At 19/1600, we see the development of scattered convective cells, labeled as cluster 8 , in the middle portion of NTR, and at 19/1630, some cells at 200-600-m elevations intensified to convective cores as cluster 8 shrunk in width, while those located above 600-m elevations to the west decayed as they moved northwestward (Figs. 11a-c). In the next hour, a small cluster 9 merged into cluster 8 , and subsequently, the latter intensified to consist of convective cores of greater than $50 \mathrm{dBZ}$ at the leading segment with weaker radar reflectivity or stratiform rainfall in the trailing region (Figs. 11d,e). Cluster 8 reached its maximum size at 19/1818, after it moved northwestward slowly with its core passing DHS from 1806 to 1842 LST, leading to an HRR of $110 \mathrm{~mm} \mathrm{~h}^{-1}$ at DHS (Figs. 11f-i). Such an intense hourly rate was composed of four higher than $14 \mathrm{~mm}(5 \mathrm{~min})^{-1}$ rainfall

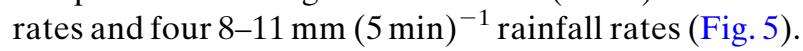
In contrast, the training region of cluster 8, passed over YJW and brought HRR of $76 \mathrm{~mm} \mathrm{~h}^{-1}$, illustrating the high rainfall production of the whole convective system.

Note the emergence of cluster 10 in the south of NTR at $19 / 1630$ that dropped rainfall of 35 and $47 \mathrm{~mm} \mathrm{~h}^{-1}$ at DJG and XUH, respectively, by 19/1900 (Figs. 11b-j). As it moved northward, it began to merge with the weakening cluster 8 . As a result, the merged system kept intensifying as it became more consolidated, dropping the extreme rainfall of $94 \mathrm{~mm} \mathrm{~h}^{-1}$ at YJW by around 19/20 (Figs. 11j-1). 

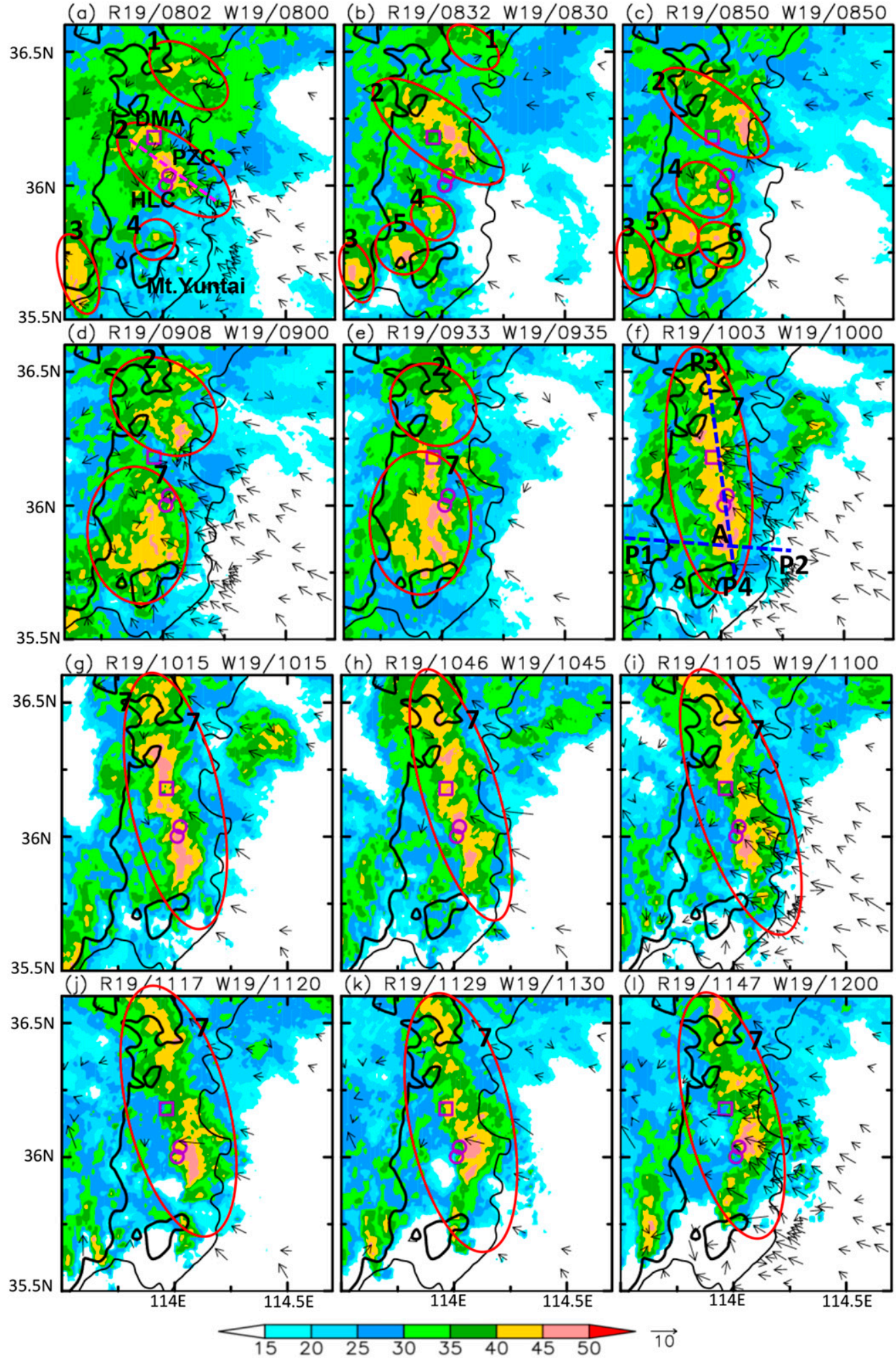

FIG. 10. Distribution of 3-km altitude CAPPI radar reflectivity (dBZ, shaded; "R") and 2-min averaged surface wind vectors ( $\mathrm{m} \mathrm{s}^{-1}$; "W") in STR (see Fig. 1) at selected times (given at the top of each panel in dd/hhnn LST) on 19 Jul. Convective cells and clusters are highlighted by red ellipses with sequence numbers. Purple hollow squares and circles denote the stations recording accumulated rainfall of higher than $600 \mathrm{~mm}$ and HRRs of greater than $100 \mathrm{~mm} \mathrm{~h}^{-1}$, respectively. Black fonts in (a) show the station names. Gray and dark gray curved lines show 200- and 600-m terrain elevation, respectively. Magenta dashed line denotes surface convergence line. 

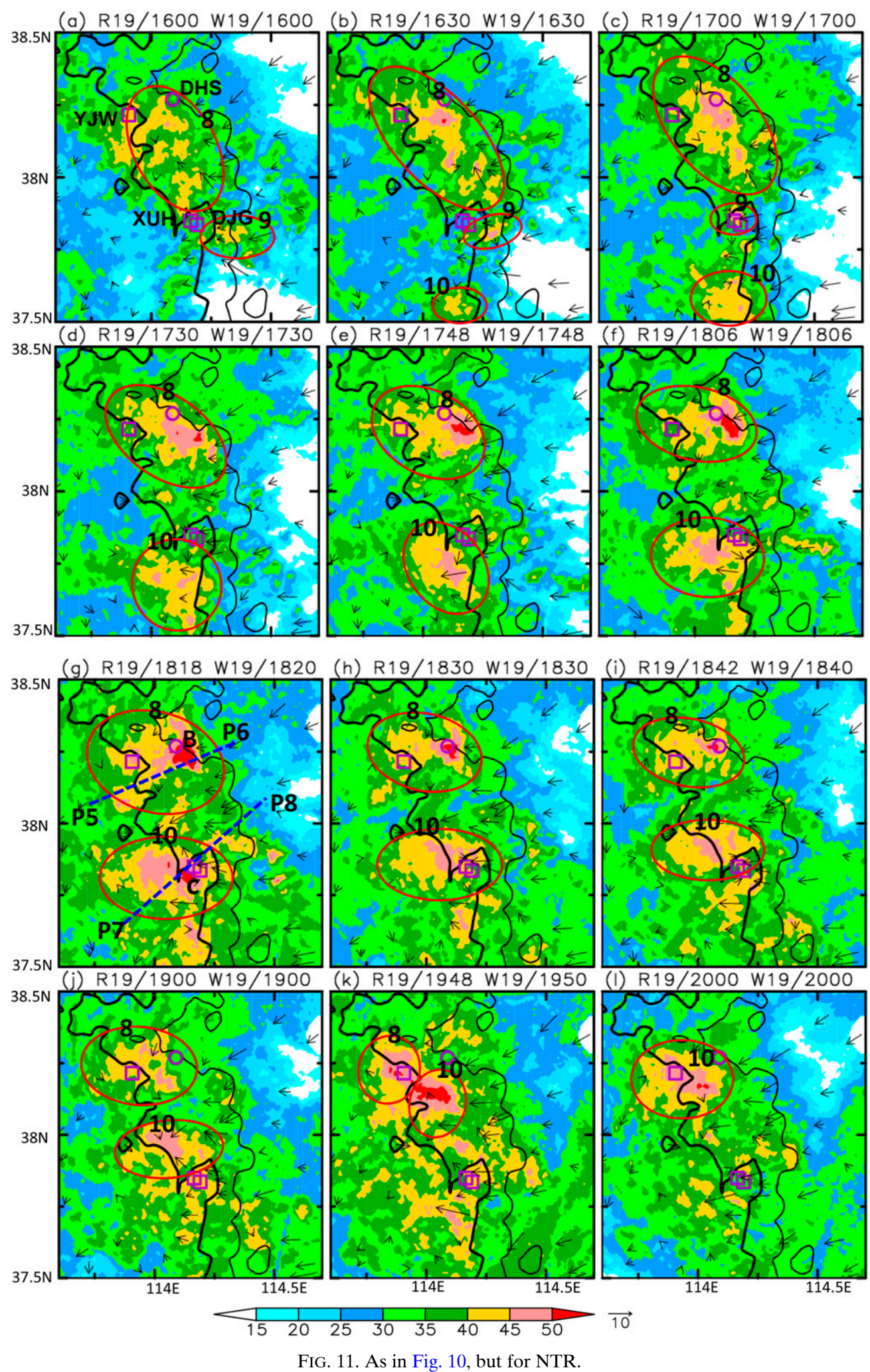
As mentioned in section 3, hourly extreme rainfall in MTR occurred during 19/21-20/01 mainly over its lower-elevation regions (Fig. 12), unlike that occurred during the earlier periods in STR and NTR. In particular, this extreme hourly rainfall episode appeared to be associated with only one cluster that formed over lower than 200-m elevated regions. The surface flow and composite reflectivity map, given in Fig. 13, shows the formation of (i) a cyclonic circulation associated with the ETC near the southeastern corner of STR, with a large area of stratiform rainfall on the east, and (ii) a line of convective clusters with weaker reflectivity and HRRs than those of cluster 11 were distributed along the lower than 600-m elevation zone; and (iii) the convergence of easterly flow with northerly flow coinciding with the linear distribution of those convective clusters. Given its large coverage on the west of the eastern foothills of Mt. Taihang, we may assume that the northerly flow represents the intrusion of cold air mass from the rear of the midlevel trough (cf. Figs. 13 and $7 \mathrm{~d}$ ), which was likely enhanced by moist downdraft air. In some sense, the convergence line shown in Fig. 13 acted like a quasi-stationary warm front such that deep convection could be triggered before reaching 200-m elevation as long as the planetary boundary layer (PBL) air was sufficiently warm and moist. This appears to be the case for cluster 11, where the approaching easterly flow became stronger than that occurred elsewhere along the eastern foothills of Mt. Taihang as the ETC moved slowly northeastward (cf. Figs. 8c,d, 12a-h, and 13). In fact, a 19/20 sounding at Xingtai to be shown later exhibited the development of an easterly LLJ of $15-17 \mathrm{~m} \mathrm{~s}^{-1}$ in the $925-850-\mathrm{hPa}$ layer. Nevertheless, we may consider the formation of cluster 11 , though over the lower-elevation region, with some indirect or weaker influences of local topography.

After its formation, cluster 11 moved northwestward slowly, and then passed by the two neighboring stations (i.e., NDG and JHX) dropping 8.8-14.7 and 5.4$16.6 \mathrm{~mm}(5 \mathrm{~min})^{-1}$ rainfall, respectively, during the period of $19 / 2202$ to $19 / 2303$ (cf. Figs. $12 \mathrm{c}-\mathrm{g}$ and 5). The wide range of 5-min rainfall rates indicates the inhomogeneous distribution of rainfall in the cluster. Despite the subsequent weaker echo intensity of cluster 11 , XHC, located over the 200-600-m terrain elevation region, continuously recorded $6-7 \mathrm{~mm}(5 \mathrm{~min})^{-1}$ rainfall, which gave an HRR of $80 \mathrm{~mm} \mathrm{~h}^{-1}$ by 20/0035 (cf. Figs. 12h-k and 5), illustrating the extreme HHRs of cluster 11 during its two different stages.

One may note that NDG recorded a higher HRR than those obtained in STR and NTR (Fig. 1b), but the extreme rainfall-producing cluster 11's $4 \mathrm{~km}$ CAPPI reflectivity was weaker. This is because CAPPI reflectivity at lower altitudes could not be obtained at the two available radars over TR due to their too far locations (see Fig. 3). This could be used to explain why large differences appeared between rainfall rates and reflectivity values. Unlike the extreme rainfall episodes in STR and NTR, the extreme rainfall episode at NDG and JHX in MTR was more related to the long-lived nature of cluster 11 (Figs. 1b, 5, and 12a-k).

It is evident from the above analysis that convective organization of the three extreme rainfall episodes in STR, NTR, and MTR differed from each other. The echo training formed a northwest-southeast-oriented convective line along a 200-600-m elevation zone in STR as the low-level southeasterly flow moved across Mt. Yuntai. In contrast, two isolated circular-shaped clusters, with convective cores in the eastern leading sector, moved slowly northwestward along a 200 600-m elevation zone, too, in NTR. Unlike those in STR and NTR, convective cores accounting for the major (secondary) extreme rainfall episode in MTR took place over lower than 200-m (over the 200-600-m) elevation regions, and their formation was more related to the development of the ETC, with indirect or weaker influences of local topography.

\section{b. Vertical structure of convective clusters}

Figure 14 shows vertical cross sections of radar reflectivity and radial velocity through the extreme rainfall-producing convective cores in the three subregions. The south-north-oriented linear-shaped convective cluster at 19/1003 (i.e., just prior to its extreme hourly rainfall occurrences at DMA, PZC, and HLC in STR) exhibited the development of weak reflectivity in the vicinity of Mt. Yuntai (i.e., at P4 in Fig. 10f), and increasing reflectivity northward until PZC and HLC (i.e., at A in Fig. 10f) where an intense extreme rainfallproducing, deep convective core was located. Weaker and shallower convective cores appeared farther northward along the linear cluster, which was consistent with the hourly rainfall distribution (cf. Figs. 10f and $14 \mathrm{~h}$ ). All these could be viewed as a result of the growth of convective cells as they moved along the linear clusters during the echo-training process (Doswell et al. 1996), and then their weakening as less convective available potential energy (CAPE) likely became available northward. The radial cross section at the southernmost convective core shows weak lowerlevel convergence (Figs. 14a,b), with negative (positive) wind speeds of -1 to $-5 \mathrm{~m} \mathrm{~s}^{-1}\left(5-10 \mathrm{~m} \mathrm{~s}^{-1}\right)$. Note that this nearly zonal cross section reflects roughly the alongline variations of the horizontal wind field, given the southeasterly wind in the environment that was nearly parallel to the linearly shaped clusters. 

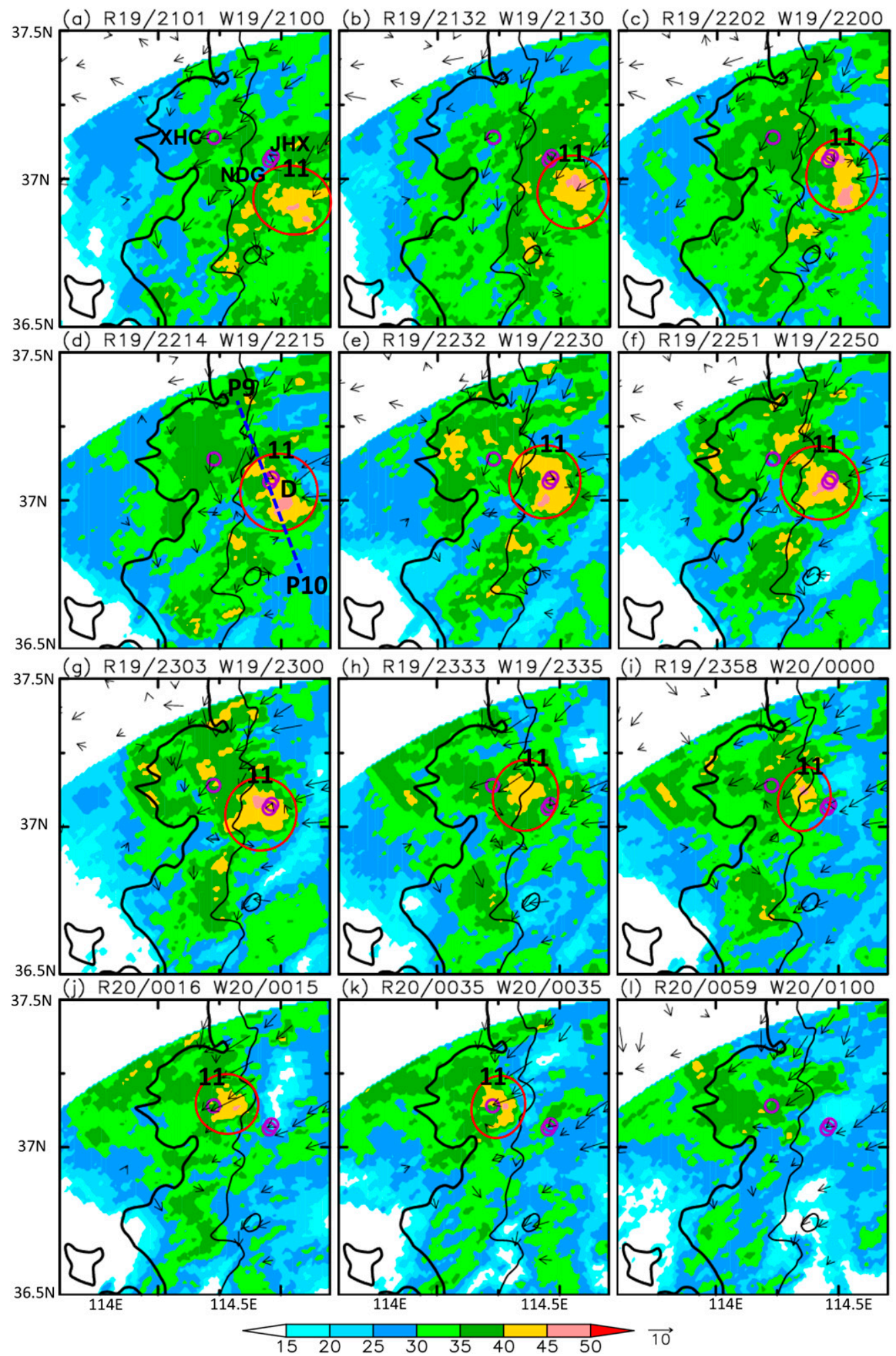

FIG. 12. As in Fig. 10, but for 4-km altitude CAPPI radar reflectivity over MTR during 2101 LST 19 Jul to 0059 LST 20 Jul 2016. 


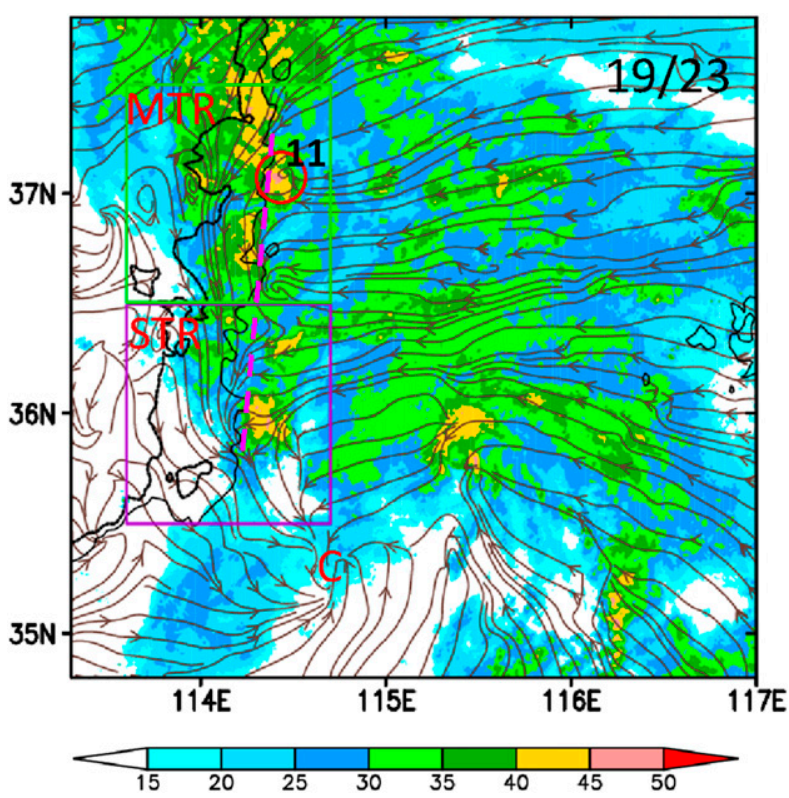

FIG. 13. Composite reflectivity (dBZ, shaded) and surface streamlines at 2300 LST 19 Jul 2016. Gray and dark gray curved lines show 200- and 600-m terrain elevation, respectively. Rectangles in purple and green denote STR and MTR, respectively Letter " $C$ " denotes the center of surface cyclonic circulation. Convective cluster 11 is highlighted by a red ellipse. A convergence line is shown by dashed lines in magenta.

In contrast, the extreme rain-producing convective cores in NTR were larger in size and more robust in reflectivity than those in STR (cf. Figs. 10f and 11g). This can be seen from a southwest-northeast cross section at 19/1818 in Figs. 14c,e, showing two isolated but intense convective cores (i.e., B and C). They were associated with the two major clusters 8 and 10 in NTR, respectively (Fig. 11g), in addition to several other isolated but smaller convective cores that were distributed outside of NTR. The top 50-dBZ layer of the most robust convective core $B$ reached as high as $6 \mathrm{~km}$ altitude, which was much higher than that of convective core A occurring in STR during an earlier extreme rainfall pe$\operatorname{riod}(\mathrm{cf}$. Figs. 14c,h). As compared to the linear structure of convective core $\mathrm{A}$, both $\mathrm{B}$ and $\mathrm{C}$ were more circular with larger area coverage (cf. Figs. 11g, 14c,e, 10f, and 14a). The differences in robustness between the two types of extreme rain-producing systems can be seen by comparing the radial flow field in Figs. 14d, f and $14 \mathrm{~b}$. The radial wind cross section through convective core B showed stronger convergence than convective core $A$, since the wind speed of $20-27 \mathrm{~m} \mathrm{~s}^{-1}$ at $0-2-\mathrm{km}$ altitudes near $B$ were much stronger than those near A (cf. Figs. 13d,b). As compared to convective core B, the lower-level easterly wind on the east of convective core $\mathrm{C}$ decreased from $15-20$ to $10-15 \mathrm{~m} \mathrm{~s}^{-1}$ (Fig. 14f) (i.e., causing much weaker convergence and a weaker core of 50-55 dBZ) (Fig. 14e).

Figure $14 \mathrm{~g}$ shows the vertical cross section through convective core D in MTR at 19/2214 that produced the highest HRR of $139 \mathrm{~mm}$ in this extreme rainfall event. Despite its too remote location from the two available radars, a convective core of $50-55 \mathrm{~dB} Z$ was evident at $3 \mathrm{~km}$ height, with the $40-\mathrm{dB} Z$ reflectivity top reaching about 6-km level, and convective core $\mathrm{D}$ was surrounded by a broad echo region with 30-40-dBZ reflectivity. Due to the lacking radar observation below 3-km altitude, no radial velocity cross section is shown.

\section{Convective initiation and maintenance}

After obtaining the relationship between terrain elevations and extreme rainfall production along the eastern foothills of Mt. Taihang, it is desirable to examine the orographic effects on convective initiation and the favorable environmental conditions for the maintenance of the extreme rain-producing clusters. Previous studies showed that orographic precipitation depends on the amount of moisture supply, and orographic lifting that is governed by the normal-tomountain wind speed $(U)$, the moist static stability of the approaching airflow $\left(N_{W}\right)$, and mountain height $\left(h_{m}\right)$, the so-called moist Froude number, $F_{W}=U /\left(N_{W} h_{m}\right)$ (Chen and Lin 2005). In addition, the orographically induced vertical motion $(w)$ can be approximately estimated by $w=-U \partial h / \partial x$, where $\partial h / \partial x$ denotes the terrain slope normal to the lower-tropospheric mean flow. Based on the results presented in the preceding sections, we may consider convective initiation as a result of lifting conditionally neutral to unstable air in the PBL over the eastern foothills of Mt. Taihang. Given the northeastward movement of the southwest vortex, the southeast movement of the ETC and the evolution of the LLJ as well as different sloping terrain conditions, it is necessary to examine separately the roles of orographic lifting in convective initiation over the three subregions of TR (i.e., STR, NTR, and MTR). Furthermore, different processes leading to extreme rainfall production from STR to NTR also suggest different convective initiation mechanisms that were operative, namely, the echo training along a northwest-southeast-oriented linear cluster under the influence of a southeasterly flow in STR, and the development of isolated circular-shaped clusters under the influences of east-to-northeasterly flows in NTR and MTR. In particular, few extreme rainfall episodes (or much lower HHRs) occurred over higher than 600-m terrain regions because of both the increased moist static stability $\left(N_{W}\right)$ after the removal of conditional 

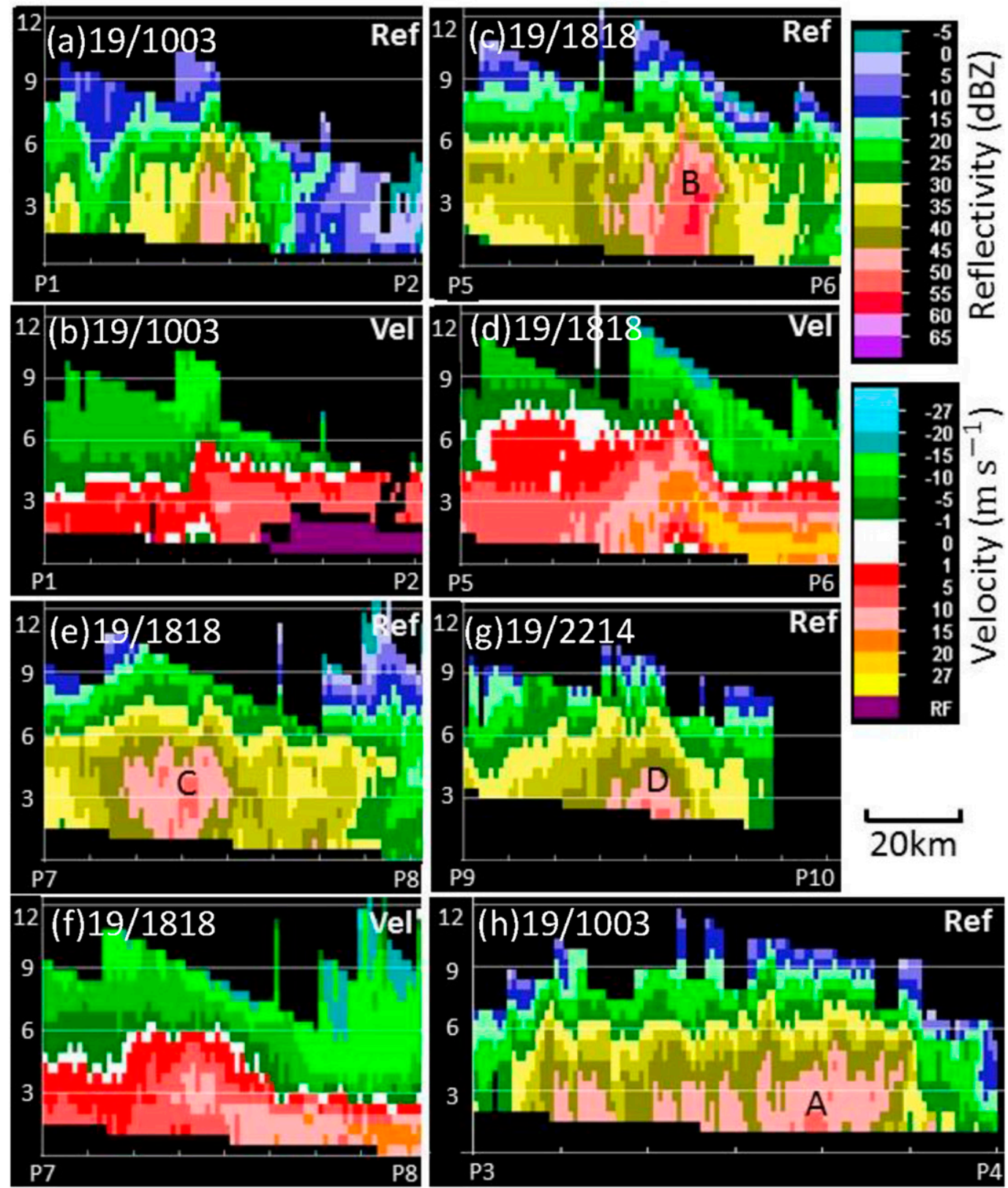

FIG. 14. Plots of (a),(c),(e) range-height indicator (RHI) reflectivity (dBZ); and (b),(d),(f) RHI velocity ( $\mathrm{m} \mathrm{s}^{-1}$ ). (a),(b); (c),(d); and (e),(f) are taken along $276^{\circ}$ azimuths at $1003 \mathrm{LST}, 256^{\circ}$ azimuths at $1818 \mathrm{LST}$, and $228^{\circ}$ azimuths at 1818 LST 19 Jul 2016, respectively. (g),(h) Vertical cross sections of radar reflectivity (dBZ) at 2214 LST and 1003 LST 19 Jul 2016, respectively. Symbols, "P1-P2," . . , and "P9-P10," denote vertical cross sections taken along lines given in Figs. 8-10. Letters "A-D" denote convective cores.

instability by deep convection over lower-elevated regions and the increased mountain elevations $\left(h_{m}\right)$.

Given the timings of convective developments shown in Figs. 10-12 and the low-level flows shown in Fig. 8, the Zhengzhou (Xingtai) sounding at 19/08 (19/20) is used to reveal the environmental conditions for convective initiation in STR (NTR and MTR) (see
Fig. 3 for the sounding locations). The Zhengzhou and Xingtai soundings were both taken upstream from clusters 7,8 , and 11 at about $3 \mathrm{~h}$ prior to their hourly extreme rainfall production time in STR, and MTR, respectively. Despite the fact that Xingtai is not located on the east of NTR (Fig. 3), we use its sounding to represent roughly the incoming 

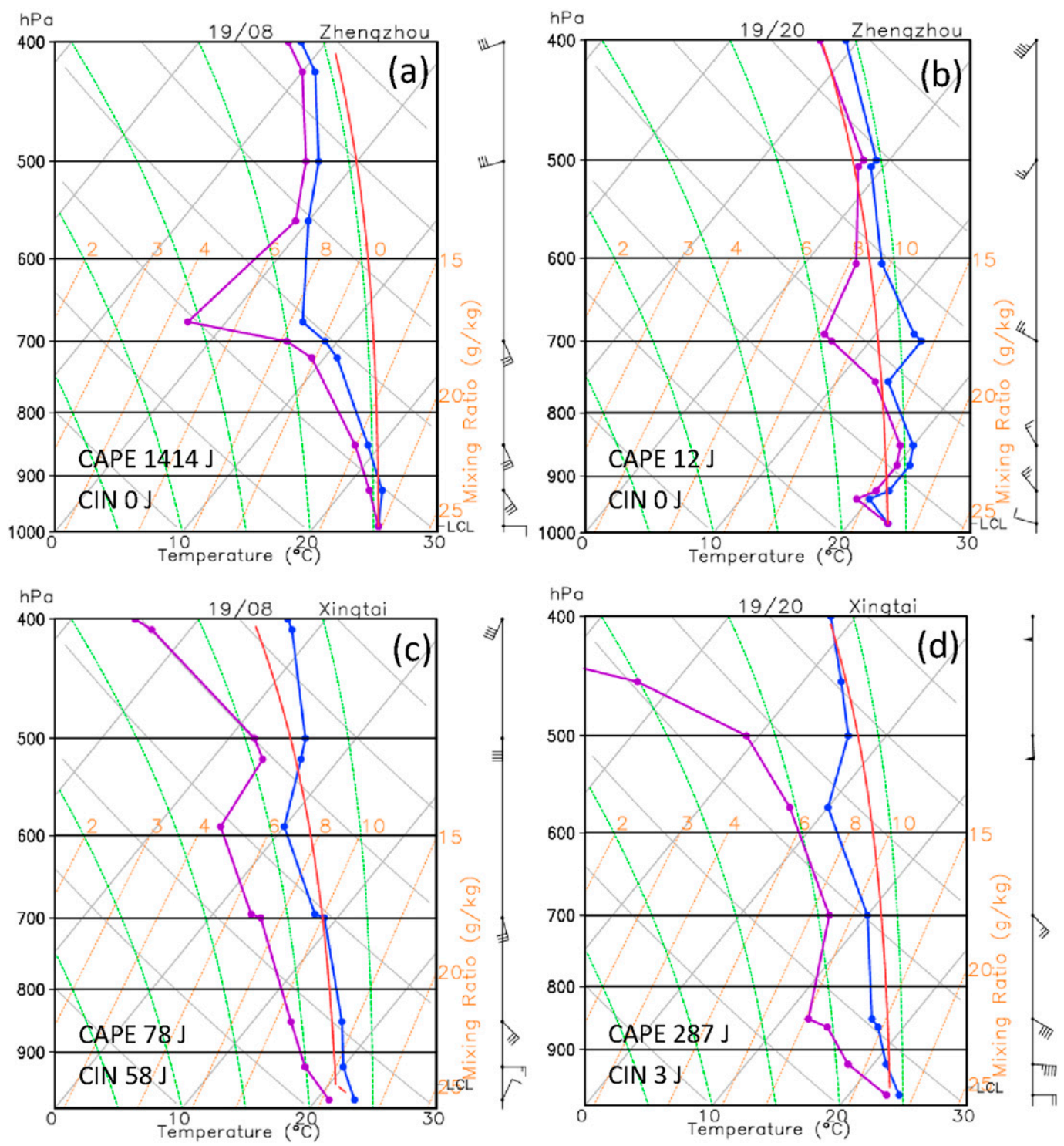

FIG. 15. Skew $T-\log p$ soundings observed at Zhengzhou at (a) 0800 LST and (b) 2000 LST; at Xingtai at (c) 0800 LST and (d) 2000 LST 19 Jul 2016. Blue, purple, and red curves represent temperature, dewpoint temperature, and parcel path from surface, respectively. A full barb is $4 \mathrm{~m} \mathrm{~s}^{-1}$. A flag (filled triangle) depicts $20 \mathrm{~m} \mathrm{~s}^{-1}$.

environmental conditions for NTR because of their close location.

It is apparent from Fig. 15a that the Zhengzhou sounding at 19/08 exhibited CAPE of $1414 \mathrm{~J}$ with little convective inhibition (CIN), and small dewpoint depression up to $400 \mathrm{hPa}$, except for a relatively dry 600 700-hPa layer, with a near-saturated surface layer. In particular, the moist, conditionally unstable air columns were embedded in the lower-tropospheric southeasterly flows of $11-12 \mathrm{~m} \mathrm{~s}^{-1}$ ahead of the linear cluster 7 (cf. Figs. 15a and 10). A meridional vertical cross section, given in Fig. 16a, shows the south- to southeasterly transport of higher equivalent potential temperature $\theta_{\mathrm{ep}}$ in the lowest inflow layers, exhibiting potential instability, into the southern portion of the linear cluster 7. Clearly, deep convection could be easily initiated at the lower foothills, given the near-saturated PBL air with small CIN but large CAPE.

Twelve hours later (i.e., at 19/20), the Zhengzhou sounding showed substantial warming above $850 \mathrm{hPa}$ due to the presence of warm advection ahead of the midlevel trough axis (cf. Figs. 15a,b and 7c,d) but a cooling layer below due likely to the passage of a cold front, as indicated by a wind directional shift from southeasterly to northwesterly in the lowest $200 \mathrm{hPa}$ (cf. Figs. 15a,b and 8b,c). This implies the stabilization 


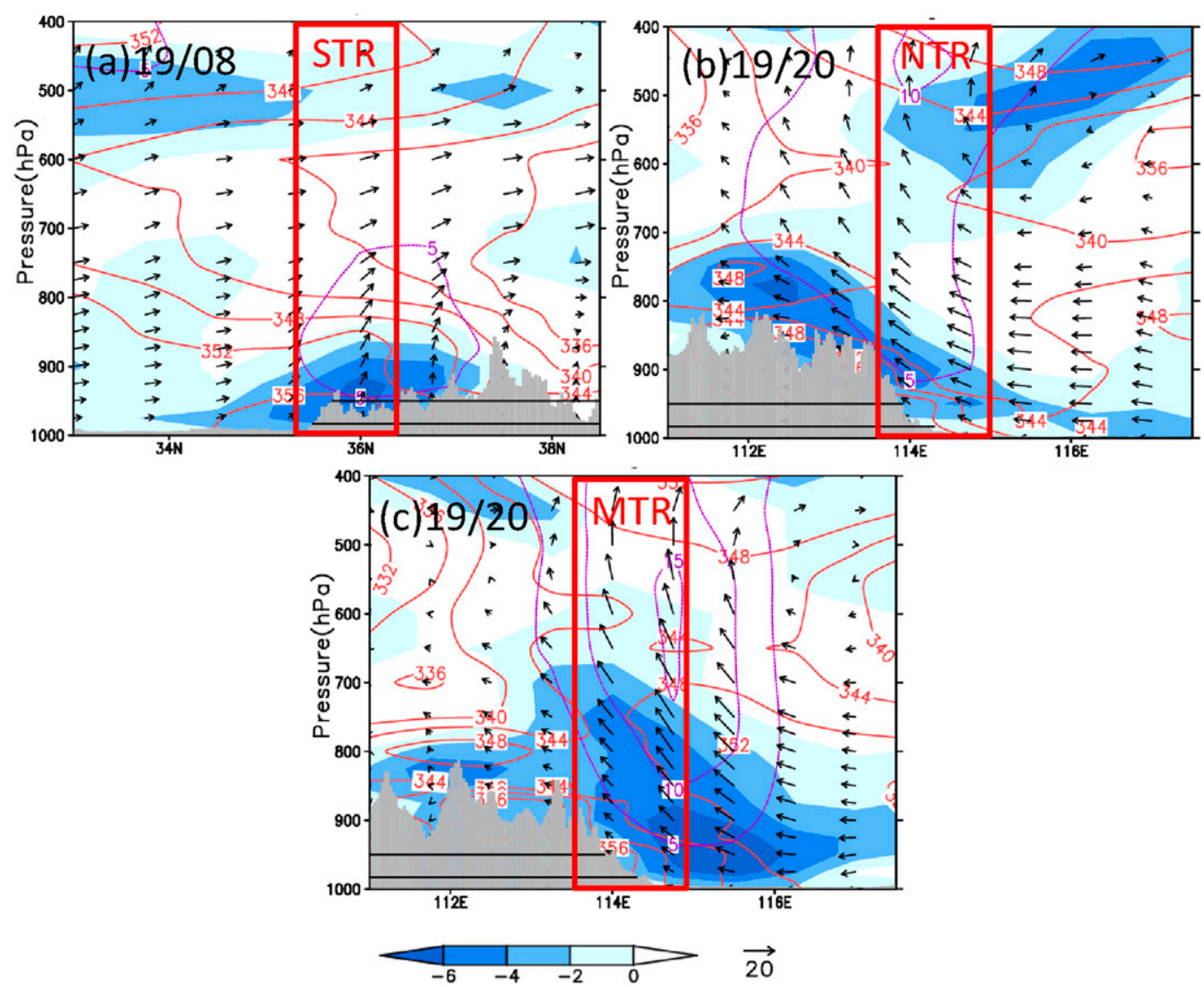

FIG. 16. Vertical cross sections of divergence $\left(10^{-5} \mathrm{~s}^{-1}\right.$, shaded), vertical velocity greater than $5 \mathrm{~cm} \mathrm{~s}^{-1}$ (purple contours), pseudoequivalent potential temperature (red contours), and composite in-plan flow vectors ( $\mathrm{m} \mathrm{s}^{-1}$ for horizontal wind and $\mathrm{cm} \mathrm{s}^{-1}$ for vertical motion) from the ERA-Interim reanalysis (a) along $114^{\circ} \mathrm{E}$ at 0800 LST; (b) along $38.25^{\circ} \mathrm{N}$ at $2000 \mathrm{LST}$; and (c) along $36.75^{\circ} \mathrm{N}$ at $2000 \mathrm{LST} 19 \mathrm{Jul} 2016$. The gray shaded area show terrain, with terrain elevations of 200 and $600 \mathrm{~m}$ shown by black lines. Red squares denote NTR, STR, and MTR.

of vertical columns, and more significantly, lacking energy supply after 19/20 for the maintenance of the linearshaped cluster 7 in STR through the echo-training process (Figs. 6 and 10).

In contrast, the Xingtai sounding at 19/08 exhibited a conditionally stable column with CIN of about $58 \mathrm{~J}$ up to $700 \mathrm{hPa}$ (Fig. 15c), although the PBL just began to develop in the presence of solar heating. The surface layer along the eastern foothills of Mt. Taihang was dominated by northeasterly flows in MTR (and NTR) that were basically driven by the lower-level pressure gradient force, given the distribution of a lower pressure to the southwest of TR (cf. Figs. 17a and 8a,b). Thus, little rainfall occurred over MTR and NTR prior to 19/11 (Fig. 6). After the daytime PBL development, the vertical column of Xingtai at 19/20 became conditionally unstable with the CAPE of $287 \mathrm{~J}$, but little CIN (Fig. 15d).

Of significance was the presence of an easterly LLJ of $12-14 \mathrm{~m} \mathrm{~s}^{-1}$ in the $925-850-\mathrm{hPa}$ layer that is nearly perpendicular to the orientation of local orography, implying that such intense moist inflow air could be lifted over the sloping surface of the eastern foothills of Mt. Taihang for convective initiation. This appears to help explain the development of isolated circularshaped cluster in NTR at the locations where the terrain gradients in the $200-600-\mathrm{m}$ elevation regions are relatively large, unlike the development of the linearshaped cluster 7 through the echo training process under the influence of a southeasterly flow in STR.

A west-east cross section, given in Fig. 16b, shows much less (and even near neutral) potential instability with smaller $\theta_{\mathrm{ep}}$ values in NTR than that in STR in the lowest $200 \mathrm{hPa}$ (e.g., an elevated peak of $348 \mathrm{~K}$ here versus greater than $356 \mathrm{~K}$ in the PBL in STR). Clearly, the lower-tropospheric convergence was much larger over the sloping surface than that over the eastern plain regions, confirming further the importance of topographical lifting in convective initiation and the maintenance of the clusters over the 200-600-m elevation regions. The presence of the much less potential instability appears to 


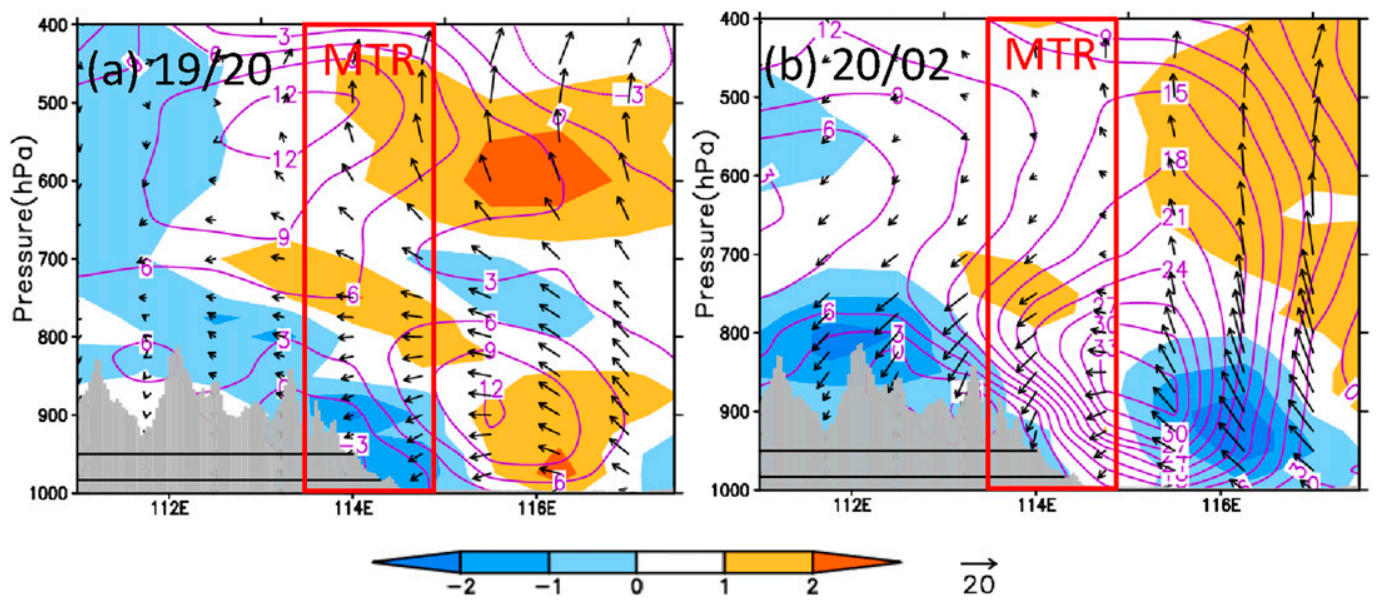

FIG. 17. Vertical cross sections of temperature advection $\left(10^{-5} \mathrm{~K} \mathrm{~s}^{-1}\right.$, shaded), relative vorticity $\left(10^{-5} \mathrm{~s}^{-1}\right.$, purple contours), and horizontal wind ( $\mathrm{m} \mathrm{s}^{-1}$ ) along $36.75^{\circ} \mathrm{N}$ from the ERA-Interim reanalysis at (a) 2000 LST 19 Jul and (b) 0200 LST $20 \mathrm{Jul} 2016$. The gray shaded areas represent terrain, with terrain elevations of 200 and $600 \mathrm{~m}$ shown by black lines. Red squares denote MTR.

account for the maintenance of cluster 10 at higher elevated terrain (i.e., around $600 \mathrm{~m}$ ) in NTR (Fig. 11). Moreover, we may attribute the absence of deep convection or another cluster between clusters 8 and 10 to the presence of the near-neutral potential instability together with relative smaller sloping terrain forcing around $38^{\circ} \mathrm{N}$ (see Fig. 11 for relatively smaller $\partial h / \partial x$ ). Few convective cells could develop above $600-\mathrm{m}$ elevations due likely to the removal of potential instability or the presence of increased moist static stability $\left(N_{W}\right)$ such that the sloping terrain tended to block the lowerlevel moist easterly flow (Fig. 16b).

As mentioned before, the extreme rainfall episode in MTR occurred in the lower-than 200-m elevated region during 19/21-20/01 (i.e., around midnight) (Fig. 6). One may wonder why this extreme rainfall episode took place after the NTR's extreme rainfall episode, rather than vice versa, as the ETC formed around 19/20. Figure 6 shows little rainfall occurring in MTR during the NTR's extreme rainfall episode, except over higher-than $600-\mathrm{m}$ elevation regions, due likely to the relatively smaller terrain gradient. More intense convection could develop in MTR around midnight because of (i) the pronounced convergence in the PBL along the eastern foothills of Mt. Taihang (Fig. 13), as mentioned before, (ii) the development of an easterly LLJ, and (iii) the warming and moistening of the PBL, as indicated by Xingtai's soundings (cf. Figs. 15c,d). In fact, Figs. 16b,c show more pronounced potential instability with higher $\theta_{\mathrm{ep}}$ values in the PBL in the incoming flow of MTR than that of NTR. Furthermore, a convergence center coinciding with the occurrence of the extreme rainfall episode was located over MTR's eastern lower-elevation region, in contrast to that over the sloping terrain in NTR (cf. Figs. 16b,c, 11, and 12c-f). The relationship between this convergence center and the intensifying ETC can be seen from Fig. 17, showing that the cyclonic vorticity increased markedly from $19 / 20$ to $20 / 02$, as could also be seen from the surface and $850-\mathrm{hPa}$ cyclonic circulation given in Fig. 13 and Figs. 8c,d, respectively. In the presence of high $-\theta_{\mathrm{ep}}$ air in the easterly flow, atmospheric columns over MTR's lower-elevation region became favorable for the development of extreme rain-producing storms. Thus, the extreme rainfall production by cluster 11 could be related to the intensification of the ETC such that potential instability in the easterly high- $\theta_{\mathrm{ep}}$ flow could be released ahead of the quasi-stationary warm front before being uplifted by the sloping terrain (Figs. 8d and 13).

\section{Summary and conclusions}

In this study, we examined the synoptic- and mesoscale processes leading to three different extreme rainfall episodes with the HRRs of greater than $100 \mathrm{~mm} \mathrm{~h}^{-1}$ over the southern, northern, and middle portions of the eastern foothills of Mt. Taihang (i.e., STR, NTR, and MTR) sequentially on 19-20 July. These extreme rainfall episodes are found to take place in a large-scale environment, in which a northwesterly traveling midlevel trough was adjoined by a slow-moving southwest vortex, leading to the genesis of an ETC to the southeast of TR with an elongated lower-tropospheric trough extending to Southwest China. As a result, a southeasterly LLJ of tropical origin ahead of the trough axis, and an 

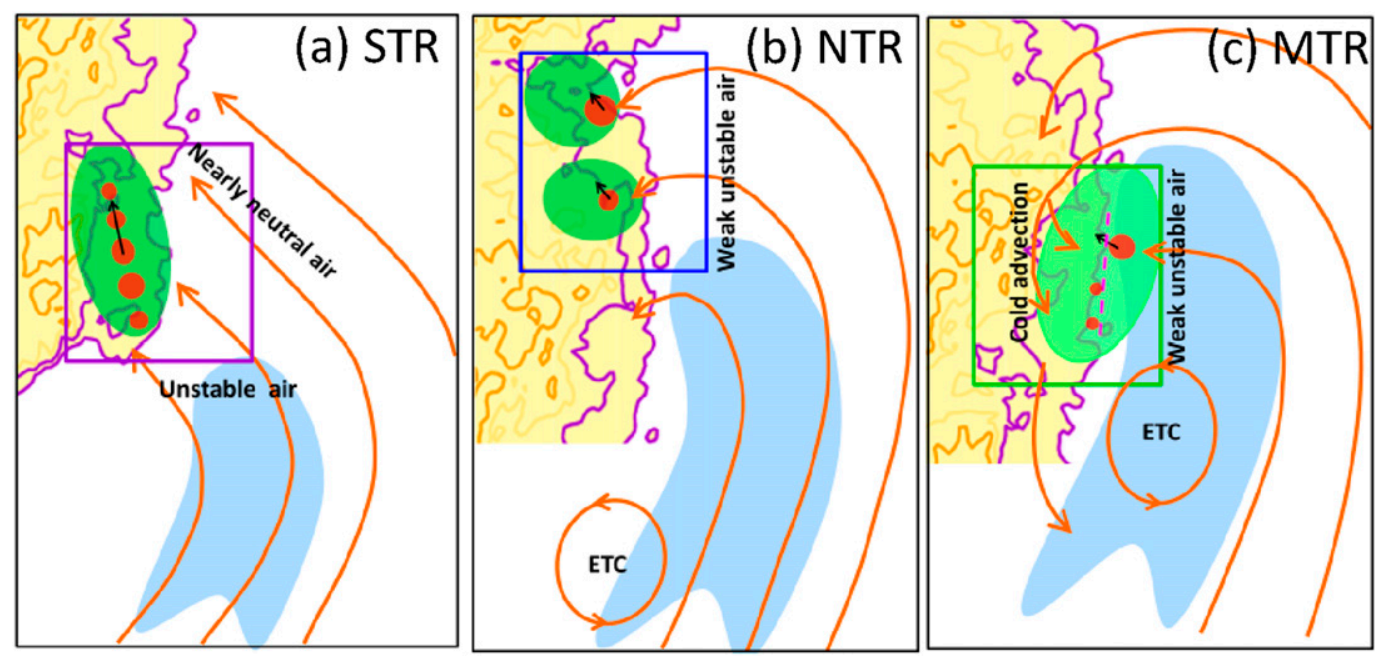

FIG. 18. Schematic diagram of low-level airflows in an ETC interacting with local topography leading to the three extreme rainfall episodes with HRRs of greater than $100 \mathrm{~mm} \mathrm{~h}^{-1}$ sequentially over (a) STR, (b) NTR, and (c) MTR along the eastern foothills of Mt. Taihang. Orange lines with arrows indicate the low-level flows with the warm and moist tongues indicated. Green and red shadings represent roughly the radar reflectivity values of 30 and $45 \mathrm{~dB} Z$ at 3-km altitude, respectively. Black arrows indicate the moving direction of extreme rain-producing convective cores. Purple curved lines represent the terrain elevations of 200 and $600 \mathrm{~m}$, respectively. Light and dark yellow curved lines represent terrain elevation of 1000 and $1400 \mathrm{~m}$, respectively. Magenta dashed lines denote a convergence line of low-level flows. Purple, blue, and green rectangles denote STR, NTR, and MTR, respectively.

easterly LLJ of oceanic origin in the northeastern quadrant of the ETC accounted for the transport of ample moisture (or high PW) into TR during the earlier and later extreme rain-producing stage, respectively. The three extreme rainfall episodes occurred as the PBL warm and moist air of varying stability was lifted by local topography of different sloping surfaces or the southward intrusion of cold air mass from North China. Upper-tropospheric divergence at the entrance region of a jet stream also appeared to help provide a favorable condition for the development of the present extreme rainfall event.

Figure 18 summarizes the convective organization of extreme rain-producing storms when approaching lower-troposphere airflows interacted in different ways with local topography in the three subregions of TR during different development stages of the ETC. During the late morning hours of 19 July, deep convection was initiated continuously as a result of the southeasterly LLJ of high $-\theta_{\text {ep }}(>356 \mathrm{~K})$ air being lifted over Mt. Yuntai (Fig. 18a). The downstream growth of the convective cells into extreme rain-producing convective cores and their subsequent decaying to weaker ones, as moving northwestward along a narrow zone of 200-600-m terrain elevation, resembled the echo training scenario, causing the formation of a convective cluster dropping extreme hourly rainfall at HLC, and PZC, and then extreme rainfall in total at DMA (all in the 200-600-m altitude range) in STR.
During the genesis of the ETC (i.e., late afternoon to early evening hours of 19 July), heavy hourly rainfall continued in STR and extended northward into high-elevated mountainous regions in MTR and the 200-600-m elevation regions in NTR. However, unlike the maintenance of a linear convective cluster in STR during the daytime period, two isolated extreme rainproducing convective clusters with trailing stratiform rainfall were formed in NTR (Fig. 18b), when conditional instability was reduced (i.e., with $\theta_{\mathrm{ep}} \sim 352 \mathrm{~K}$ in the PBL). Their developments appeared to be aided by the generation of an easterly LLJ associated with the intensifying ETC that was nearly normal to the orientation of Mt. Taihang, especially over NTR's 200-600-m altitude range portion where the terrain elevation gradients are large (i.e., near DHS, YJW, DJG, and XUH).

By the midnight of 19 July, the cold air from the rear of the midlevel trough intruded the eastern foothills of Mt. Taihang, accounting for the formation of a southnorth-oriented convergence line and along-line convective clusters in MTR as the easterly flow met with the cold northerly flow under the influence of the intensifying ETC (Fig. 18c). In particular, the increased potential instability (i.e., with $\theta_{\mathrm{ep}}>356 \mathrm{~K}$ in the PBL) resulting from the enhanced easterly LLJ of high- $\theta_{\mathrm{ep}}$ air facilitated the development of an intense convective core in MTR before the moist PBL air reached 200600-m elevation zone. This convective core dropped 
extreme hourly rainfall at NDG and JHX, and then extreme rainfall in total at $\mathrm{XHC}$, as moving upslope from the lower elevation to the 200-600-m elevation range, but with much less topographical influences compared to the other two extreme rainfall episodes occurring in NTR and STR.

Based on the above results, we may conclude that given the favorable large-scale conditions with ample moisture supply by the LLJs of oceanic origins, the timings and locations of the observed extreme rainfall scenarios in TR were determined by the extent of potential instability and saturation of air parcels in the PBL, the genesis of the ETC, the strength of lower-level approaching airflows and their directions with respect to the orientation of local topography as well as the slope of complex topography along the eastern foothills of Mt. Taihang. In particular, the anomalous genesis location of the ETC and its subsequent northward movement along the orientation of Mt. Taihang appear to be two of the major factors accounting for the extreme rainfall occurring along the eastern foothills in MTR and NTR. Furthermore, we wish to emphasize that the extreme HRRs of greater than $100 \mathrm{~mm} \mathrm{~h}^{-1}$ occurred mostly over the 200-600-m elevated zones in NTR and STR, due likely to the presence of intense normal-to-mountain flow with near-saturated conditions in the lowest sloping layers, and that few extreme rainfall episodes occurred over higher than $600-\mathrm{m}$ elevation regions due to the significantly reduced Froude number values associated with increased moist static stability and more elevated mountains. Of course, the above conclusions from the present observational analyses are limited due to the lack of three-dimensional high-resolution data. Some cloud-permitting modeling studies should be performed in the future in order to gain further insight into the exact convective initiation over the complex topography (e.g., over the 200-600-m elevated sloping zones), and the roles of moist downdrafts and the intensifying ETC as well as some cloud microphysical processes in generating the observed extreme hourly rainfall rates and their spatiotemporal sequences over TR. In a forthcoming article, we will examine in more detail what anomalous largerscale and climatological features resulted in the present extreme rainfall event and the other heavy rainfall events from central to North China.

Acknowledgments. We are grateful to Dr. Russ S. Schumacher and three anonymous reviewers for their constructive comments that helped improve the quality of the manuscript. This work was supported by the National Basic Research Program of
China (Grant 2018YFC1507403) and Scientific Development Program of Chinese Academy of Meteorological Sciences (Grant 2018KJ040).

\section{REFERENCES}

Baik, J. J., Y. H. Kim, and H. Y. Chun, 2001: Dry and moist convection forced by an urban heat island. J. Appl. Meteor., 40, 1462-1475, https://doi.org/10.1175/1520-0450(2001)040<1462: $\mathrm{DAMCFB}>2.0 . \mathrm{CO} ; 2$.

Bao, X., and F. Zhang, 2013: Impacts of the mountain-plains solenoid and cold pool dynamics on the diurnal variation of warm-season precipitation over northern China. Atmos. Chem. Phys., 13, 6965-6982, https://doi.org/10.5194/ acp-13-6965-2013.

Bluestein, H. B., and M. H. Jain, 1985: Formation of mesoscale lines of precipitation: Severe squall lines in Oklahoma during the spring. J. Atmos. Sci., 42, 1711-1732, https://doi.org/ 10.1175/1520-0469(1985)042<1711:FOMLOP $>2.0$.CO;2.

Chen, M., Y. Wang, F. Gao, and X. Xiao, 2012: Diurnal variations in convective storm activity over contiguous North China during the warm season based on radar mosaic climatology. J. Geophys. Res., 117, D20115, https://doi.org/10.1029/ 2012JD018158.

Chen, S.-H., and Y.-L. Lin, 2005: Effects of moist Froude number and CAPE on a conditionally unstable flow over a mesoscale mountain ridge. J. Atmos. Sci., 62, 331-350, https://doi.org/ 10.1175/JAS-3380.1.

Chen, T. J. G., and C. C. Yu, 1988: Study of low-level jet and extremely heavy rainfall over northern Taiwan in the mei-yu season. Mon. Wea. Rev., 116, 884-891, https://doi.org/10.1175/ 1520-0493(1988)116<0884:SOLLJA > 2.0.CO;2.

Chen, X., K. Zhao, and M. Xue, 2014: Spatial and temporal characteristics of warm season convection over Pearl River Delta region, China, based on 3 years of operational radar data. J. Geophys. Res. Atmos., 119, 12 447-12 465, https://doi.org/ 10.1002/2014JD021965.

Corfidi, S. F., 2003: Cold pools and MCS propagation: Forecasting the motion of downwind-developing MCSs. Wea. Forecasting, 18, 997-1017, https://doi.org/10.1175/ 1520-0434(2003)018<0997:CPAMPF >2.0.CO;2.

Crum, T. D., and R. L. Alberty, 1993: The WSR-88D and the WSR88D operational support facility. Bull. Amer. Meteor. Soc., 74, 1669-1687, https://doi.org/10.1175/1520-0477(1993)074<1669: TWATWO $>2.0 . \mathrm{CO} ; 2$.

Doswell, C. A., III, H. E. Brooks, and R. A. Maddox, 1996: Flash flood forecasting: An ingredients-based methodology. Wea. Forecasting, 11, 560-581, https://doi.org/10.1175/1520-0434(1996) $011<0560$ :FFFAIB $>2.0$. CO 2 .

Durkee, J. D., L. Campbell, K. Berry, D. Jordan, G. Goodrich, R. Mahmood, and S. Foster,, 2012: A synoptic perspective of the record 1-2 May 2010 mid-South heavy precipitation event. Bull. Amer. Meteor. Soc., 93, 611-620, https://doi.org/10.1175/ BAMS-D-11-00076.1.

He, H., and F. Zhang, 2010: Diurnal variations of warm-season precipitation over northern China. Mon. Wea. Rev., 138, 1017-1025, https://doi.org/10.1175/2010MWR3356.1.

Houze, R. A., Jr., 2012: Orographic effects on precipitating clouds. Rev. Geophys., 50, RG1001, https://doi.org/10.1029/ 2011RG000365.

Hu, K., R. Lu, and D. Wang, 2010: Seasonal climatology of cut-off lows and associated precipitation patterns over Northeast 
China. Meteor. Atmos. Phys., 106, 37-48, https://doi.org/ 10.1007/s00703-009-0049-0.

Jessup, S. M., and S. J. Colucci, 2012: Organization of flash-floodproducing precipitation in the northeast United States. Wea. Forecasting, 27, 345-361, https://doi.org/10.1175/WAF-D-1100026.1.

Lei, L., J. Sun, N. He, Z. Liu, and J. Zeng, 2017: A study on the mechanism for the vortex system evolution and development during the torrential rain event in North China on 20 July 2016 (in Chinese). Acta Meteor. Sin., 75, 685-699.

Li, H., X. Cui, and D.-L. Zhang, 2017a: On the initiation of an isolated heavy-rain-producing storm near the central urban area of the Beijing metropolitan region. Mon. Wea. Rev., 145, 181-197, https://doi.org/10.1175/MWR-D-16-0115.1.

,$- \ldots$, and $\_, 2017 \mathrm{~b}$ : A statistical analysis of hourly heavy rainfall events over the Beijing metropolitan region during the warm seasons of 2007-2014. Int. J. Climatol., 37, 4027-4042, https://doi.org/10.1002/joc.4983.

Lin, Y.-L., S. Chiao, T. Wang, M. L. Kaplan, and R. P. Weglarz, 2001: Some common ingredients for heavy orographic rainfall. Wea. Forecasting, 16, 633-660, https://doi.org/10.1175/15200434(2001)016<0633:SCIFHO > 2.0.CO;2.

Luo, Y., and Y. Chen, 2015: Investigation of the predictability and physical mechanisms of an extreme-rainfall-producing mesoscale convective system along the Meiyu front in East China: An ensemble approach. J. Geophys. Res. Atmos., 120, 10 593-10 618, https://doi.org/10.1002/2015JD023584.

—_, Y. Gong, and D.-L. Zhang, 2014: Initiation and organizational modes of an extreme-rain-producing mesoscale convective system along a mei-yu front in East China. Mon. Wea. Rev., 142, 203-221, https://doi.org/10.1175/ MWR-D-13-00111.1.

_- M. Wu, F. Ren, J. Li, and W. Wong, 2016: Synoptic situations of extreme hourly precipitation over China. J. Climate, 29, 8703-8719, https://doi.org/10.1175/JCLI-D-16-0057.1.

Moore, B. J., P. J. Neiman, F. M. Ralph, and F. E. Barthold, 2012: Physical processes associated with heavy flooding rainfall in Nashville, Tennessee, and vicinity during 1-2 May 2010: The role of an atmospheric river and mesoscale convective systems. Mon. Wea. Rev., 140, 358-378, https://doi.org/10.1175/ MWR-D-11-00126.1.

Parker, M. D., and R. H. Johnson, 2000: Organizational modes of midlatitude mesoscale convective systems. Mon. Wea. Rev., 128, 3413-3436, https://doi.org/10.1175/1520-0493(2001) $129<3413$ :OMOMMC $>2.0 . \mathrm{CO} ; 2$.

Rebora, N., and Coauthors, 2013: Extreme rainfall in the Mediterranean: What can we learn from observations? J. Hydrometeor., 14, 906-922, https://doi.org/10.1175/JHM-D-12-083.1.

Schumacher, R. S., 2017: Heavy rainfall and flash flood. Oxford Research Encyclopedia of Natural Hazard Science, https:// doi.org/10.1093/acrefore/9780199389407.013.132.

, and R. H. Johnson, 2005: Organization and environmental properties of extreme-rain-producing mesoscale convective systems. Mon. Wea. Rev., 133, 961-976, https://doi.org/ 10.1175/MWR2899.1.

- and - 2006: Characteristics of U.S. extreme rain events during 1999-2003. Wea. Forecasting, 21, 69-85, https://doi.org/ 10.1175/WAF900.1.

_, and —, 2009: Quasi-stationary, extreme-rain-producing convective systems associated with midlevel cyclonic circulations. Wea. Forecasting, 24, 555-574, https://doi.org/ 10.1175/2008WAF2222173.1.
Steiner, M., R. A. Houze, and S. E. Yuter, 1995: Climatological characterization of three-dimensional storm structure from operational radar and rain gauge data. J. Appl. Meteor., 34, 1978-2007, https://doi.org/10.1175/1520-0450(1995)034<1978: CCOTDS $>2.0 . \mathrm{CO} ; 2$.

$\mathrm{Su}$, Y., and Coauthors, 2011: A study of temporal-spatial distribution and synoptic characteristics of severe convective weather in Beijing, Tianjin and Hebei (in Chinese). Meteor. Mon., 37, 177-184.

Tao, S., 1980: Heavy Rainfalls in China (in Chinese). Science Press, 225 pp.

Wang, H., and Coauthors, 2009: Development and application of the Doppler weather radar 3-D digital mosaic system (in Chinese). J. Appl. Meteor. Sci., 20, 241-224.

_ , Y. Luo, and B. J. D. Jou, 2014: Initiation, maintenance, and properties of convection in an extreme rainfall event during SCMREX: Observational analysis. J. Geophys. Res. Atmos., 119, 13 206-13 232, https://doi.org/10.1002/2014JD022339.

Xia, R., D.-L. Zhang, C. Zhang, and Y. Wang, 2018: Synoptic control of convective rainfall rates and cloud-to-ground lightning frequencies in warm-season mesoscale convective systems over North China. Mon. Wea. Rev., 146, 813-831, https://doi.org/10.1175/MWR-D-17-0172.1.

Xu, W., E. J. Zipser, Y.-L. Chen, C. Liu, Y. Liou, W. Lee, and B. Jong-Dao Jou, 2012: An orography-associated extreme rainfall event during TiMREX: Initiation, storm evolution, and maintenance. Mon. Wea. Rev., 140, 2555-2574, https:// doi.org/10.1175/MWR-D-11-00208.1.

Yu, X., and Coauthors, 2006: The Principle and Operational Application of Doppler Weather Radar (in Chinese). China Meteorological Press, 314 pp.

Zhang, D.-L., and J. M. Fritsch, 1986: Numerical simulation of the meso- $\beta$ scale structure and evolution of the 1977 Johnstown flood. Part I: Model description and verification. J. Atmos. Sci., 43, 1913-1943, https://doi.org/10.1175/ 1520-0469(1986)043<1913:NSOTMS > 2.0.CO;2.

_- Y. Lin, P. Zhao, X. Yu, S. Wang, H. Kang, and Y. Ding, 2013: The Beijing extreme rainfall of 21 July 2012: "Right results" but for wrong reasons. Geophys. Res. Lett., 40 , 1426-1431, https://doi.org/10.1002/grl.50304.

Zhang, M., and D.-L. Zhang, 2012: Sub-kilometer simulation of a torrential-rain-producing mesoscale convective system in East China. Part I: Model verification and convective organization. Mon. Wea. Rev., 140, 184-201, https://doi.org/10.1175/ MWR-D-11-00029.1.

Zheng, L., J. Sun, X. Zhang, and C. Liu, 2013: Organizational modes of mesoscale convective systems over Central East China. Wea. Forecasting, 28, 1081-1098, https://doi.org/ 10.1175/WAF-D-12-00088.1.

Zhong, L., R. Mu, D. Zhang, P. Zhao, Z. Zhang, and N. Wang, 2015: An observational analysis of warm-sector rainfall characteristics associated with the 21 July 2012 Beijing extreme rainfall event. J. Geophys. Res. Atmos., 120,3274-3291, https:// doi.org/10.1002/2015JA021425.

Zhong, S., and X. Q. Yang, 2015: Ensemble simulations of the urban effect on a summer rainfall event in the Great Beijing Metropolitan Area. Atmos. Res., 153,318-334, https://doi.org/ 10.1016/j.atmosres.2014.09.005.

Zhu, Y., and R. E. Newell, 1998: A proposed algorithm for moisture fluxes from atmospheric rivers. Mon. Wea. Rev., 126, 725-735, https://doi.org/10.1175/1520-0493(1998)126<0725: APAFMF $>2.0 . \mathrm{CO} ; 2$. 